\title{
Proposta de metodologia simplificada para o dimensionamento de pavimentos com revestimento primário
}

\section{Leandro Olivio Nervis ${ }^{1}$}

${ }^{1}$ Universidade de Santa Cruz do Sul, UNISC, leandron@unisc.br

\section{Recebido:}

28 de março de 2018

Aceito para publicação:

06 de novembro de 2017

Publicado:

30 de abril de 2018

Editor de área:

Jorge Barbosa Soares

\section{Palavras-chaves:}

Pavimento,

Revestimento Primário,

Dimensionamento.

\section{Keywords:}

Pavement,

Unsurfaced Gravel Roads, Design.

DOI:10.14295/transportes.v26i1.1352

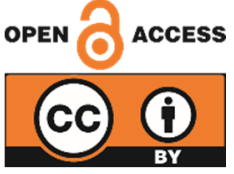

\begin{abstract}
RESUMO
Neste trabalho, é apresentada uma proposta de metodologia simplificada para o dimensionamento de pavimentos com revestimento primário, concebida a partir de conceitos da Teoria da Elasticidade, Mecânica dos Solos e Mecânica dos Pavimentos. A metodologia abrange a definição da(s) espessura(s) da(s) camada(s) de revestimento primário, quando necessárias, para resistir às cargas verticais de modo a não ocorrer a ruptura ao cisalhamento de uma ou mais camadas do pavimento e minimizar as deformações permanentes acumuladas. Além disso, é tratada a capacidade da camada de rolamento resistir aos esforços horizontais. A proposta tem como características ser de natureza analítica, mas demandar como parâmetros experimentais, somente a coesão e o ângulo de atrito das camadas. Tais parâmetros podem ser obtidos a partir de ensaios triaxiais ou de cisalhamento direto, ou numa forma mais simplificada, somente com a resistência à compressão simples obtida a partir de ensaios de compressão simples e a resistência à tração obtida a partir do ensaio de compressão diametral.
\end{abstract}

\begin{abstract}
This paper presents a simplified methodology proposal for the design of unsurfaced gravel roads pavements, which was conceived from the concepts of Elasticity Theory, Soil Mechanics and Pavement Mechanics. The methodology encompasses defining the thickness of the wearing course layers, when necessary, to withstand the vertical loads so as not to break shear one or more layers of the pavement to minimize the accumulated permanent deformations. Further, the ability of the bearing layer to withstand horizontal stresses is treated. The purpose of the proposal is to be of a analytical nature, but to require as experimental parameters only the cohesion and angle of friction of the layers. This parameters can be obtained from triaxial or direct shear tests, or in a more simplified form, only the unconfined compressive strength, which is obtained from unconfined compression tests and the splitting tensile strength, which is obtained from diametral compression tests.
\end{abstract}

\section{INTRODUÇÃO}

As vias terrestres sem revestimento clássico (asfalto, concreto ou calçamento), providas ou não de revestimento primário, de acordo com o Departamento Nacional de Infraestrutura de Transportes - DNIT (2016), representam 86,5\% do total da malha viária nacional, totalizando mais de 1,3 milhões de quilômetros. Embora o custo por quilômetro para a implantação e manutenção dessas vias seja significativamente menor do que aquelas providas de revestimento clássico, o custo acumulado atinge valores elevados, tendo em vista a grande extensão de sua malha.

O revestimento primário constitui-se de uma ou mais camadas compactadas de solo, material granular (composto por agregados naturais e/ou artificiais), cascalho, saibro ou piçarra, com características adequadas. Ele é aplicado diretamente sobre o subleito compactado e regularizado com a função de assegurar condições satisfatórias de tráfego, mesmo sob condições climáticas adversas, em qualquer época 
do ano (DNIT, 2005; DER PR, 2005).

Vários defeitos são típicos de ocorrência em pavimentos com revestimento primário. Nervis (2016) reuniu esses defeitos, segundo suas características, em dois grupos: os de natureza não estrutural e os de ordem estrutural. Os primeiros envolvem a durabilidade da pista associada às questões climáticas e à ação abrasiva do tráfego e o atendimento das questões relacionadas ao conforto do usuário e à degradação mecânica dos veículos, vinculando-se os defeitos de poeira, desagregação, falta de aderência com a pista molhada, rugosidade excessiva, corrugações e sulcos de erosão. Por outro lado, os aspectos estruturais envolvem a capacidade de suporte do conjunto formado pelas camadas de revestimento primário e subleito quando submetidos à ação dos carregamentos oriundos do tráfego, abrangendo a previsão de comportamento em relação ao surgimento e evolução dos defeitos de afundamento de trilha de roda, ruptura ao cisalhamento, arrancamento de partículas e atoleiros.

No presente trabalho não são abordadas questões referentes à seleção de materiais para emprego nas camadas de revestimento primário. 0 foco é a definição da(s) espessura(s) da(s) camada(s) de revestimento primário, quando necessárias, com materiais previamente selecionados, para resistir às cargas verticais de modo que não ocorra a ruptura ao cisalhamento de uma ou mais camadas do pavimento e que as deformações permanentes acumuladas sejam minimizadas. Esses propósitos são alcançados através da adoção de um Fator de Segurança (FS) que, além de ter a função de cobrir as incertezas oriundas dos modelos de cálculo, dos ensaios e de eventuais heterogeneidades das camadas, venha a garantir um bom afastamento da condição de ruptura. Além disso, é tratada a capacidade da camada de rolamento resistir aos esforços horizontais sem apresentar ruptura ao cisalhamento, o que ocasionaria um elevado arrancamento de partículas. Tal proposta de metodologia simplificada para o dimensionamento desse tipo de pavimento é baseada numa abordagem de natureza analítica apoiada nos conceitos da Teoria da Elasticidade, Mecânica dos Solos e Mecânica dos Pavimentos.

As poucas propostas para o dimensionamento de pavimentos com revestimento primário encontradas na literatura na sua maioria se resumem aos modelos de natureza empírica ou aos catálogos com valores tabelados de espessuras de camadas a serem adotadas, também obtidos de maneira empírica. Em ambas as situações, o dimensionamento é função do Índice de Suporte Califórnia (ISC) ou CBR (California Bearing Ratio).

No enfoque analítico, o pavimento é tratado como uma estrutura de engenharia e seu dimensionamento se dá em função do carregamento e da resistência dos materiais, assim como é feito com as estruturas de concreto ou de aço. Assim, tal abordagem possibilita a utilização de materiais para os quais ainda não se tenha experiência suficiente em campo. A resistência das camadas é expressa pelos parâmetros de Mohr-Coulomb, permitindo incluir a consideração da influência da sucção. As metodologias empíricas se mostram limitadas à medida que não há garantia de correlação entre CBR e resistência ao cisalhamento e deformações permanentes, conforme demonstrado no trabalho publicado por Nervis (2016). Além disso, a aplicação de um modelo analítico se torna possível para condições ambientais e de tráfego diferentes daquelas para as quais os métodos empíricos foram desenvolvidos.

\section{PROPOSTAS DE DIMENSIONAMENTO ENCONTRADAS NA LITERATURA}

\subsection{Especificação do South Dakota Local Transportation Assistance Program (SD LTAP)}

Para a determinação da espessura da camada de revestimento, a referida especificação, a qual foi desenvolvida por Skorseth e Selim (2000), recomenda o emprego de uma das duas opções de procedimentos. A primeira é baseada em métodos gráficos e a segunda utiliza um catálogo de dimensionamento de pavimentos.

0 procedimento gráfico é baseado no modelo de previsão de desempenho mecanístico-empírico da AASHTO (American Association of State Highway and Transportation Officials), o qual leva em conta aspectos relacionados à deformabilidade dos materiais, demandando como dados de entrada os Módulos de Resiliência (MRs) do subleito e da camada de revestimento, magnitude e número de repetições de carga. 
O modelo ainda considera o clima regional de onde estará inserida a obra e a variação sazonal dos módulos de resiliência dos materiais e das cargas.

O procedimento alternativo para a determinação da espessura da camada de revestimento primário consiste na utilização de catálogos. Uma aproximação similar para tal procedimento é sugerida pela agência local e por outras agências do estado de Dakota do Sul para determinar a espessura da camada de revestimento primário. Os autores alertam que o método é um tanto simplista, uma vez que é baseado somente em dois parâmetros: tráfego de caminhões pesados e condições de suporte do subleito dado pelo CBR. A Tabela 1 traz um exemplo de catálogo, o qual consta na especificação em questão e apresenta sugestões para espessuras do revestimento primário em função desses parâmetros.

Tabela 1: Sugestão de espessura de camada de revestimento primário para vias rurais a serem implantadas ou reconstruídas. Fonte: Skorseth e Selim, 2000

\begin{tabular}{|c|c|c|}
\hline $\begin{array}{l}\text { Estimativa do número de passagens diárias de } \\
\text { caminhões pesados }\end{array}$ & Condições de suporte do subleito $^{1}$ & Espessura mínima sugerida $(\mathrm{cm})$ \\
\hline \multirow{3}{*}{0 a 5} & Baixa & 16,5 \\
\hline & Média & 14,0 \\
\hline & Alta & 11,5 \\
\hline \multirow{3}{*}{5 a 10} & Baixa & 21,5 \\
\hline & Média & 18,0 \\
\hline & Alta & 14,0 \\
\hline \multirow{3}{*}{10 a 25} & Baixa & 29,0 \\
\hline & Média & 13,0 \\
\hline & Alta & 18,0 \\
\hline \multirow{3}{*}{25 a 50} & Baixa & 37,0 \\
\hline & Média & 29,0 \\
\hline & Alta & 21,5 \\
\hline
\end{tabular}

${ }^{1}$ Baixa Capacidade de Suporte: $\mathrm{CBR} \leq 3 \%$;

Média Capacidade de Suporte: $3 \% \leq \mathrm{CBR} \leq 10 \%$;

Alta Capacidade de Suporte: $C B R \geq 10 \%$.

\subsection{Especificações do Departamento de Transportes da República da África do Sul (Draft TRH 20 - The Structural Design, Construction and Maintenance of Unpaved Roads)}

Essa especificação, a qual foi elaborada por Paige-Green (1990), preconiza a utilização do modelo da Equação 1 para o dimensionamento da espessura da camada de revestimento primário.

$$
T=t\left(1+\frac{C_{t}}{100}\right)+G L_{p} L_{d}
$$

onde:

T: espessura da camada ( $\mathrm{mm})$;

t: espessura mínima demandada para garantir a proteção do subleito $(\mathrm{mm})$;

$\mathrm{C}_{\mathrm{t}}$ : compactação induzida pelo tráfego (\%);

$\mathrm{GL}_{\mathrm{p}}$ : perda anual de material prevista $(\mathrm{mm})$;

$\mathrm{L}_{\mathrm{d}}$ : vida de projeto da via ou frequência de restauração.

Para a espessura mínima demandada para garantir a proteção do subleito (t), a especificação prevê que a mesma pode ser excluída do modelo da Equação 1 para subleitos que apresentarem CBR de campo superior a $5 \%$ e recomenda um valor nominal de $50 \mathrm{~mm}$ para subleitos com CBR menor que $5 \%$.

A grandeza da compactação induzida pelo tráfego $\left(\mathrm{C}_{\mathrm{t}}\right)$ se refere à diminuição da espessura da camada ocasionada pela compactação induzida pela ação do tráfego, dada em porcentagem em relação à espessura original construída. Considerando a execução da compactação através de 3 passagens de rolo, a especificação sugere como aproximações estimadas potenciais de perda de espessura de revestimento de $10 \%$ e $20 \%$ para compactações com rolo pé-de-carneiro executadas próximo a umidade ótimo e abaixo dela, respectivamente, e de 5\% para o caso de compactação executada com rolo pneumático na 
condição próxima a umidade ótima. A especificação prevê que a perda anual de material prevista (GLp) pode ser fixada, com um bom nível de confiança, na ordem de $11 \mathrm{~mm}$ por ano.

\subsection{O Método do DNER para dimensionamento de pavimentos flexíveis}

Esse método, apresentado no Manual de Pavimentação do DNIT (2006), possui natureza empírica, pois é embasado em observações de desempenho de pavimentos, associando número de repetições de carga com valores de CBR das camadas. Embora seja destinado ao dimensionamento de pavimentos asfálticos, pode ser empregado para estruturas mais simples, como pavimentos com revestimento primário, suprimindo-se as camadas superiores e levando em conta a existência do revestimento primário.

A essência do método é garantir que o pavimento não sofra ruptura precocemente. Um ábaco fornece a espessura total do pavimento, em termos de material granular, em função do CBR e do número de repetições de carga ou operações de um eixo padrão de 8,2 t. Na sequência, determinam-se as espessuras das camadas, também em termos de material granular. Por fim, as espessuras das camadas de revestimento primário são obtidas pela resolução sucessiva de inequações e o emprego de coeficientes de equivalência estrutural. 0 método se encontra melhor descrito no Manual de Pavimentação do DNIT (2006).

Villibor et al. (2009) expõe que o coeficiente de equivalência estrutural de uma camada "i" de reforço pode ser obtida em função do valor do CBR da camada e o da camada subjacente, conforme Equação 2.

onde:

$$
K_{i}=\sqrt[3]{\frac{C B R_{i}}{C B R_{(i-1)}}}
$$

$\mathrm{K}_{\mathrm{i}}$ : coeficiente de equivalência estrutural de uma camada de reforço "i";

$\mathrm{CBR}_{\mathrm{i}}$ : valor do CBR da camada "i";

$\mathrm{CBR}_{(\mathrm{i}-1)}$ : valor do CBR da camada subjacente à camada "i".

Segundo os autores, mesmo que o os valores de $\mathrm{CBRi}_{\text {e }} \mathrm{CBR}_{(\mathrm{i}-1)}$ sejam superiores a $30 \%$, para efeito de cálculo eles devem ser limitados a esse valor.

\subsection{Modelo de capacidade de carga de fundações proposto por Vésic (1975)}

O modelo proposto por Vésic (1975) apud Medina e Motta (2005) consiste num método analítico para determinar a capacidade de suporte de fundações assentes sobre camadas estratificadas, cujos dados de entrada são os parâmetros de resistência ao cisalhamento. Segundo Medina e Motta (2005), tal modelo, o qual é exposto na sequência (Equações 3 a 5), pode ser empregado para a avaliação da condição limite de suporte quanto à ruptura plástica de um pavimento.

$$
\begin{gathered}
q_{0}=\left[q_{0}{ }^{\prime \prime}+\left(\frac{1}{K}\right) c_{1} \cot g\left(\varnothing_{1}\right)\right] e^{2\left[1+\frac{B}{L}\right] \operatorname{Ktg}\left(\varnothing_{1}\right)\left(\frac{H}{B}\right)}-\left(\frac{1}{K}\right) c_{1} \cot g\left(\varnothing_{1}\right) \\
K=\frac{1-\operatorname{sen}^{2} \emptyset_{1}}{1+\operatorname{sen}^{2} \emptyset_{1}} \\
q_{0}{ }^{\prime \prime}=c N_{c} S_{c}+q N_{q} S_{q}+\frac{1}{2} \gamma B N_{\gamma} S_{\gamma}
\end{gathered}
$$

onde:

$\mathrm{q}_{0}$ : capacidade de carga da fundação assente diretamente sobre a camada superior;

q0": capacidade de carga da fundação assente diretamente sobre a camada inferior;

$c_{1}$ e $\emptyset_{1}$ : parâmetros de coesão e ângulo de atrito interno da camada superior;

c e ø: parâmetros de coesão e ângulo de atrito interno da camada inferior;

B: menor dimensão da área de carregamento;

L: maior dimensão da área de carregamento;

H: espessura da camada superior; 
$\mathrm{N}_{\mathrm{c}}, \mathrm{N}_{\mathrm{q}}$ e $\mathrm{N}_{\gamma}$ : fatores de carga;

$\mathrm{S}_{\mathrm{c}}, \mathrm{S}_{\mathrm{q}}$ e $\mathrm{S}_{\gamma}$ : fatores de forma da fundação;

q: tensão efetiva do solo na cota de apoio da fundação.

Os fatores de carga $\mathrm{N}_{c}, \mathrm{~N}_{\mathrm{q}}$ e $\mathrm{N}_{\gamma}$ são dados pelas Equações 6, 7 e 8.

$$
\begin{gathered}
N_{q}=e^{\pi \operatorname{tg}^{\prime}\left(\boldsymbol{\prime}^{\prime}\right) \operatorname{tg}^{2}\left(45^{\circ}+\frac{\varnothing}{2}\right)} \\
N_{c}=\left(N_{q}-1\right) \cot g(\varnothing) \\
N_{\gamma}=2\left(N_{q}+1\right) \operatorname{tg}(\varnothing)
\end{gathered}
$$

Os fatores de forma, para o caso específico de fundações circulares são dados pelas Equações 9, 10 e 11.

$$
\begin{gathered}
S_{c}=1+\frac{N_{q}}{N_{c}} \\
S_{q}=1+\operatorname{tg}(\varnothing) \\
S_{\gamma}=0,60
\end{gathered}
$$

Oloo, Fredlund e Gan (1997) propuseram uma metodologia baseada nos mesmos conceitos, porém considerando somente a camada de topo, o que torna o problema demasiadamente simplificado, por negligenciar as camadas subjacentes, em especial o subleito. Por outro lado, os autores consideraram no seu trabalho a influência da sucção em solos não saturados na resistência ao cisalhamento, cuja abordagem pode ser aplicada no presente modelo e no presente trabalho.

\section{PROPOSTA DE DIMENSIONAMENTO COM BASE NA ANÁLISE DE TENSÕES}

\subsection{Capacidade do pavimento a resistir às cargas verticais}

Na Figura 1 é representada esquematicamente uma estrutura qualquer de pavimento com revestimento primário. Uma avaliação se as camadas irão sofrer ruptura por cisalhamento devido ao carregamento vertical pode ser feita, verificando se o nível de tensões atuante no ponto médio das camadas de revestimento e no topo do subleito resultam numa tensão de cisalhamento que venha a ultrapassar a sua resistência ao cisalhamento. Isso pode ser ilustrado através do gráfico da Figura 2, onde para dada tensão principal menor $\sigma_{3}$, existe uma tensão principal maior máxima $\sigma_{1 \max }$ tal que o círculo de Mohr correspondente não ultrapasse a envoltória de ruptura de Mohr-Coulumb do material.

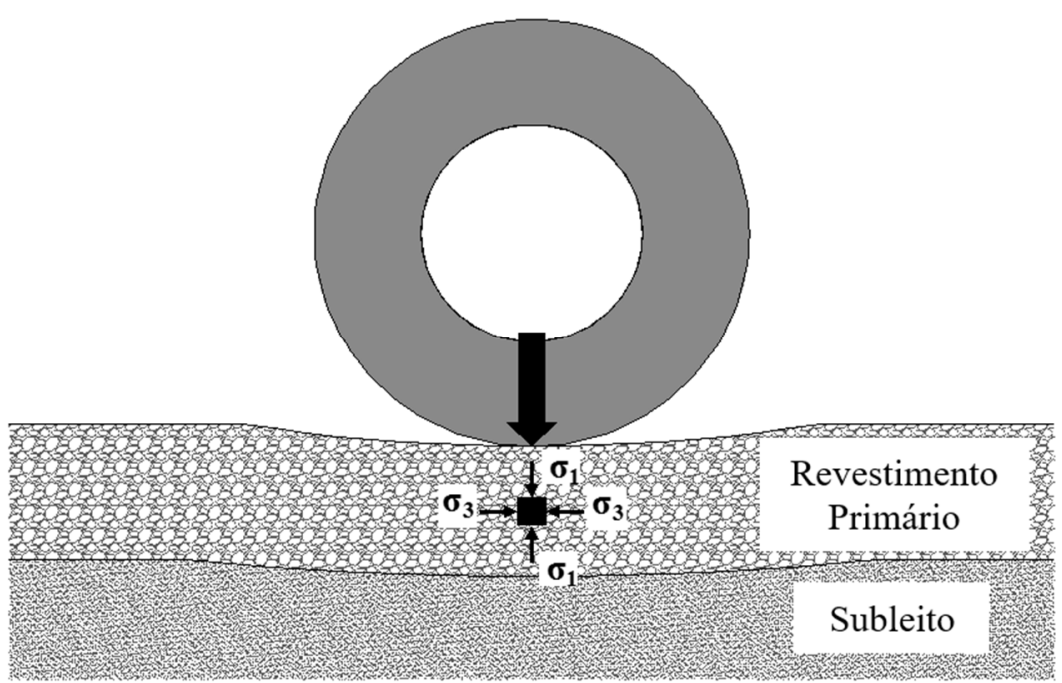

Figura 1. Tensões atuantes num ponto qualquer de um pavimento com revestimento primário 


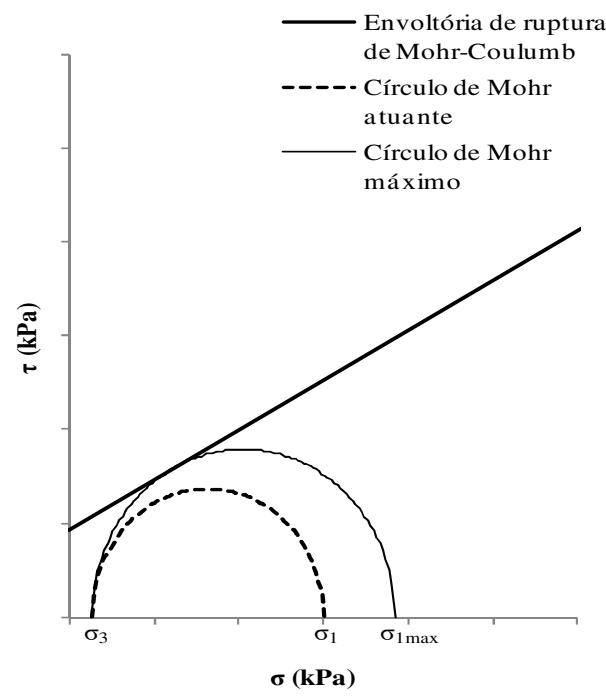

Figura 2: Gráfico que representa as tensões principais atuantes num ponto qualquer de uma camada de pavimento frente a sua resistência ao cisalhamento

Conforme Das e Sobhan (2014), a tensão $\sigma_{1 \max }$ pode ser determinada pela Equação 12 , onde c e ø são, respectivamente, o intercepto de coesão e o ângulo de atrito interno do material.

$$
\sigma_{1 \text { max }}=\sigma_{3} \operatorname{tg}^{2}\left(45^{\circ}+\frac{\varnothing}{2}\right)+2 c t g\left(45^{\circ}+\frac{\varnothing}{2}\right)
$$

A partir disso é possível definir um Fator de Segurança FS (Equação 13), o qual consiste na razão entre o círculo de Mohr-Coulumb máximo para dada tensão principal menor $\sigma_{3}$ e o círculo de MohrCoulumb atuante. Valores de FS abaixo de 1 significam que o círculo de Mohr atuante no ponto em análise está ultrapassando o limite de resistência do material representada pela envoltória de Mohr-Coulomb.

$$
F S=\frac{\sigma_{1 \max }-\sigma_{3}}{\sigma_{1}-\sigma_{3}}
$$

Na condição limite de ruptura, as deformações são excessivas. Então, torna-se necessário aplicar um FS que, além de cobrir as incertezas oriundas dos modelos de cálculo, dos ensaios e de eventuais heterogeneidades das camadas (materiais e compactação), sirva também para limitar as deformações em níveis aceitáveis. Oloo, Fredlund e Gan (1997) apresentam valores de FS recomendados por alguns autores, os quais constam na Tabela 2.

Tabela 2: Fatores de segurança recomendados para uso em pavimentos com revestimento primário. Fonte: Oloo, Fredlund e Gan, 1997

\begin{tabular}{lll}
\hline Referência & Fator de Segurança (FS) & Observações \\
\hline Broms (1963) & 2 & Baixo volume de tráfego \\
\hline Broms (1963) & 3 & Alto volume de tráfego \\
\hline $\begin{array}{l}\text { Bender e Barenberg } \\
\text { (1978) }\end{array}$ & 1,6 & $\begin{array}{l}\text { Sobre a resistência ao cisa- } \\
\text { Ihamento do subleito }\end{array}$ \\
\hline Sellmeijer et al. (1982) & 1,5 & $\begin{array}{l}\text { Sobre a resistência ao } \\
\text { cisalhamento do subleito }\end{array}$ \\
\hline Giroud e Noiray (1981) & 1,6 & $\begin{array}{l}\text { Sobre a resistência ao } \\
\text { cisalhamento do subleito }\end{array}$ \\
\hline
\end{tabular}

Salienta-se que não há uma definição objetiva do que são estradas de baixo e de alto volume de tráfego, uma vez que há variações entre países, regiões de um mesmo país ou mesmo Estado. Bernucci (1995) e Nogami e Villibor (1995) consideram baixo volume de tráfego quando o valor de N para um 
período de 10 anos é de no máximo 106. Keller e Sherar (2003) e AASHTO (2011) definem que estradas de baixo volume de tráfego são aquelas que apresentam uma média de tráfego menor que 400 veículos por dia. 0 DNIT não estabelece uma definição. Entretanto, em seu Manual de Conservação Rodoviária (2005), expõe que para estradas que possuam volume diário de tráfego de 200 a 300 veículos, torna-se mais vantajoso economicamente pavimentá-las do que mantê-las com revestimento primário, em razão da exaustão das jazidas economicamente viáveis e, principalmente, pelo custo de operação dos veículos. Com base no descrito acima, tem-se que a grande maioria das vias terrestres sem revestimento clássico provavelmente se enquadrem como de baixo volume de tráfego. Assim, dos FSs apresentados na Tabela 2, o valor de 2 se apresenta como a melhor escolha, pois não se restringe a incidir somente sobre a resistência do subleito (situação menos segura) e não é tão conservador quanto a adoção de um valor igual a 3, sugerido para estradas de alto volume de tráfego.

O pavimento pode ser constituído por uma ou mais camadas de revestimento primário. 0 procedimento aqui proposto para o seu dimensionamento consiste em atribuir espessuras para a(s) camada(s) e calcular os FSs em pontos de interesse, buscando-se, por tentativas, a otimização do problema. Uma vez sendo considerado como carregamento um Eixo Simples de Roda Dupla (ESRD), como por exemplo, o eixo padrão do DNIT, os pontos de interesse são aqueles posicionados sob o eixo das rodas e no alinhamento correspondente a posição intermediária entre as rodas, no ponto médio das camadas de revestimento primário e no topo do subleito. Na Figura 3 é apresentada uma representação esquemática do problema para um exemplo de pavimento composto de duas camadas de revestimento primário.

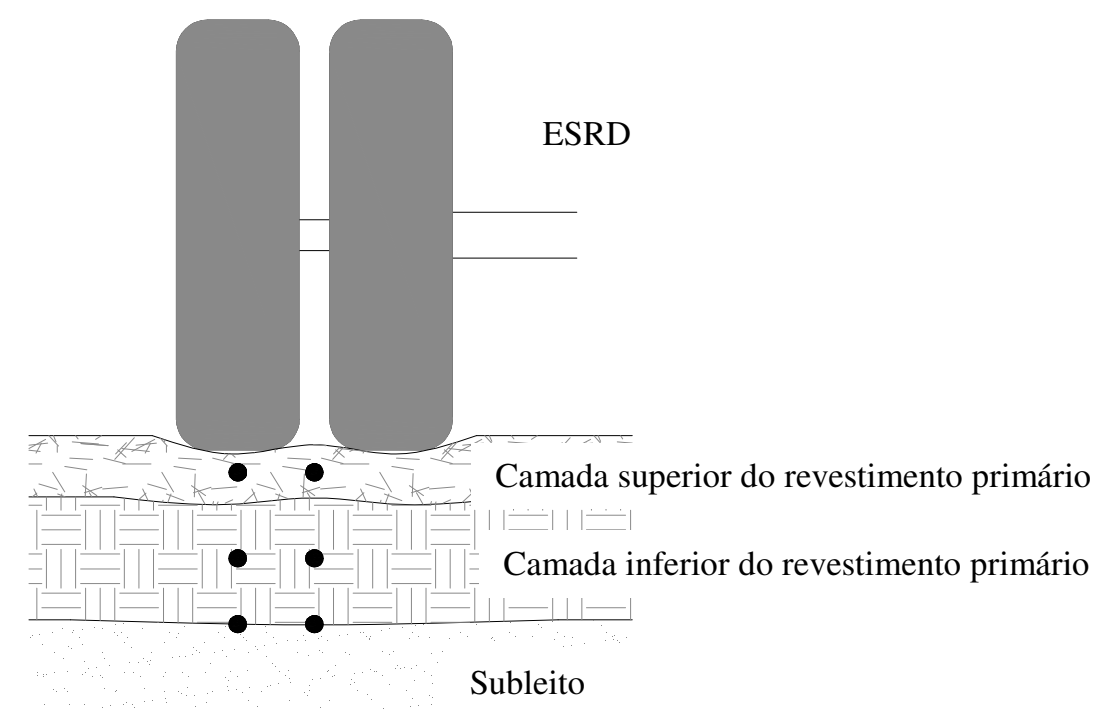

Figura 3: Pontos de interesse para a verificação dos FSs em um pavimento com revestimento primário

A proposta de dimensionamento apresentada neste trabalho é baseada em carregamentos estáticos. Entretanto, os pavimentos são solicitados por cargas repetidas. Assim, torna-se necessário a introdução de um método que incorpore o efeito das cargas repetidas. Para tal, Oloo, Fredlund e Gan (1997) sugerem a conversão contida na Equação 14, devendo a pressão de inflação dos pneus permanecer constante.

$$
P_{S}=\frac{P}{\left(1 / N_{\text {AASHTO }}\right)^{0,25}}
$$

onde:

$\mathrm{P}_{\mathrm{S}}$ : carga axial estática equivalente;

P: carga de projeto;

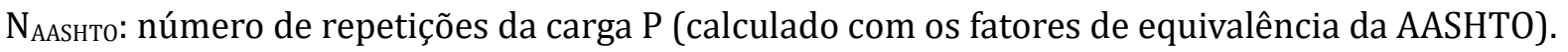




\subsection{Capacidade do pavimento em resistir às cargas horizontais}

Os esforços de tracionamento e frenagem dos veículos, além daqueles decorrentes da força centrípeta que surge nos trechos em curva, podem causar a ruptura ao cisalhamento da porção superficial da camada de rolamento, caso ultrapasse sua resistência ao cisalhamento. Isso ocorrendo, é arrancada uma substancial quantidade de partículas, gerando diminuição da espessura dessa camada e depressões na pista. Não deve ser confundido aqui o arrancamento de partículas devido ao mecanismo de adesão delas ao pneu, o que a depender da natureza do material, pode ocorrer principalmente quando a pista está molhada.

Uma forma simplificada de tratar a questão, parte da definição de um fator de segurança (FS) dada pela razão entre a resistência ao cisalhamento $\tau$ do material e a tensão horizontal atuante (f), conforme Equação 15, onde a tensão horizontal atuante, de acordo com a Equação 16, é igual ao coeficiente de atrito $(\mu)$ entre o pneu e a pista vezes a tensão vertical $(\sigma)$.

$$
\begin{aligned}
& F S=\frac{\tau}{f} \\
& f=\mu \sigma
\end{aligned}
$$

Para fins de projeto, sugerem-se os valores para FS recomendados por Broms (1963) apud Oloo, Fredlund e Gan (1997) apresentados na Tabela 2, de forma a cobrir as incertezas oriundas do modelo de cálculo, dos ensaios e de eventuais heterogeneidades das camadas (materiais e compactação). Quando esses valores não são atingidos, deve-se melhorar a resistência ao cisalhamento $\tau$ do material, seja pelo aumento da energia de compactação, estabilização granulométrica ou química ou substituição do material por outro mais resistente.

\section{METODOLOGIA SIMPLIFICADA PARA A OBTENÇÃO DAS TENSÕES ATUANTES EM UM PONTO DO PAVIMENTO}

Tratando-se o pavimento com revestimento primário de uma estrutura estratificada composta pelo subleito e uma ou mais camadas de revestimento primário, tem-se que a maneira mais racional para a previsão das tensões atuantes em um ponto qualquer dessa estrutura é através de uma análise mecanística. Porém, esse tipo de análise demanda como dado de entrada o Módulo de Resiliência (MR) das camadas de revestimento primário e do subleito. Ocorre que, o ensaio para a determinação do MR demanda tempo e custos desproporcionais para a finalidade em questão, além de que poucos laboratórios no Brasil o realizam, tornando pouco provável a sua obtenção.

Para efeitos de anteprojeto de pavimentos, algumas referências propõe a estimativa do MR através da modelagem a partir de outros parâmetros mais simples. Um modelo clássico é aquele proposto por Heukelom e Klomp (1962) apud Medina e Motta (1995) que correlaciona o MR com o CBR in situ. Entretanto, os autores alertam que a penetração CBR submete a amostra a deformações plásticas elevadas, ao passo que o MR se determina a pequenas deformações após grande número de ciclos de carregamento e descarregamentos, o que torna o modelo pouco confiável. Medina e Motta (2005) citam trabalhos que resultaram em equações de regressão do MR com um ou mais parâmetros, tais como, massa específica aparente seca, CBR, porcentagem de silte, fração inferior a 0,002 mm e Mini-CBR. Constata-se que tais equações são empíricas, sendo um tanto quanto limitada sua extrapolação, uma vez que só são aplicadas para o universo estudado. O Manual de dimensionamento mecanístico-empírico de pavimentos da AASHTO (2008) apresenta uma estimativa do valor do MR para camadas de base, subbase, aterro e subleito em função da classificação dos materiais pelo sistema da AASHTO, o que também se constitui num processo empírico.

Por outro lado, tem-se que para o caso de pavimentos com revestimento primário, os valores de MR frequentemente não apresentam diferenças tão abruptas entre uma camada e outra e o subleito, como ocorre, por exemplo, no caso dos pavimentos asfálticos. Desta forma, considerando-se a hipótese de que o valor do MR possa ser admitido constante para todas as camadas e o subleito, é possível empregar um 
método derivado da equação de Boussinesq para o cálculo das tensões nos pontos de interesse do pavimento, o qual independe do valor do MR, desde que isso não repercuta em diferenças substanciais nos valores obtidos para as tensões nos pontos de interesse, o que será discutido mais adiante.

Das (2008) apresenta um modelo, concebido a partir da integração da equação de Boussinesq, que permite calcular as tensões atuantes em pontos localizados abaixo de uma área flexível circular de carregamento uniforme q e raio b e um substrato homogêneo infinito (MR constante), conforme representado na Figura 4. Esse modelo prevê que as tensões num ponto $\mathrm{P}$ localizado a uma profundidade $\mathrm{z}$ sob o centro da placa circular são dadas pelas Equações 17 e 18, onde v é o coeficiente de Poisson do material.

$$
\begin{gathered}
\sigma_{z}=q\left[1-\frac{z^{3}}{\left(b^{2}+z^{2}\right)^{3 / 2}}\right] \\
\sigma_{r}=\sigma_{\theta}=q\left[1+2 v-\frac{2(1+v) z}{\left(b^{2}+z^{2}\right)^{1 / 2}}+\frac{z^{3}}{\left(b^{2}+z^{2}\right)^{3 / 2}}\right]
\end{gathered}
$$

As tensões num ponto $\mathrm{P}^{\prime}$ a uma profundidade $\mathrm{z}$ abaixo da placa circular localizado num alinhamento afastado a uma distância s do centro da placa circular são dadas pelas Equações 19, 20, 21 e 22 onde A', B', C, D, E, F e G são função de s/b e z/b, cujos valores foram tabelados por Ahlvin e Ulery (1962) apud Das (2008) e são apresentados nos Anexos 1 a 7 do presente artigo.

$$
\begin{gathered}
\sigma_{z}=q\left(A^{\prime}+B^{\prime}\right) \\
\sigma_{r}=q\left[2 v A^{\prime}+C+(1-2 v) F\right] \\
\sigma_{\theta}=q\left[2 v A^{\prime}-D+(1-2 v) E\right] \\
\tau_{r z}=\tau_{z r}=q G
\end{gathered}
$$

De acordo com Medina e Motta (2005), valores usuais para o coeficiente de Poisson v são 0,35 para materiais granulares e 0,45 para solos argilosos.

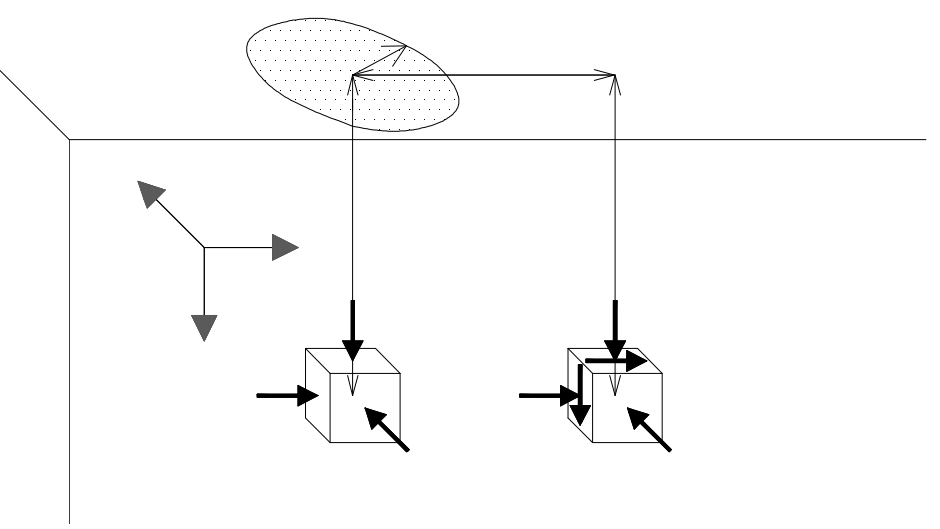

Figura 4: Tensões em pontos abaixo de uma área circular uniformemente carregada

Uma vez calculadas as tensões $\sigma_{\mathrm{z}}, \sigma_{\mathrm{r}}, \sigma_{\theta}, \tau_{\mathrm{rz}}$ e $\tau_{\mathrm{zr}}$ num ponto qualquer, determinam-se as tensões principais $\sigma_{\mathrm{a}}, \sigma_{\mathrm{b}}$ e $\sigma_{\mathrm{c}}$ através das Equações 23, 24 e 25. A maior dessas três tensões é definida como a tensão principal maior $\sigma_{1}$ e a menor delas como a tensão principal menor $\sigma_{3}$, conforme representado pelas equações 26 e 27.

$$
\begin{gathered}
\sigma_{\mathrm{a}}=\frac{\sigma_{\mathrm{z}}+\sigma_{\mathrm{r}}}{2}+\sqrt{\left[\frac{\left(\sigma_{\mathrm{z}}-\sigma_{\mathrm{r}}\right)}{2}\right]^{2}+\tau_{\mathrm{rz}}^{2}} \\
\sigma_{b}=\frac{\sigma_{z}+\sigma_{r}}{2}-\sqrt{\left[\frac{\left(\sigma_{z}-\sigma_{r}\right)}{2}\right]^{2}+\tau_{r z}^{2}}
\end{gathered}
$$




$$
\begin{gathered}
\sigma_{c}=\sigma_{\theta} \\
\sigma_{1}=\operatorname{MAIOR}\left[\sigma_{a} ; \sigma_{b} ; \sigma_{c}\right] \\
\sigma_{3}=\operatorname{MENOR}\left[\sigma_{a} ; \sigma_{b} ; \sigma_{c}\right]
\end{gathered}
$$

Com a finalidade de testar a metodologia apresentada acima para a obtenção das tensões atuantes no pavimento de uma maneira mais simplificada, ou seja, considerando-se um substrato homogêneo infinito (MR constante), foram tomadas como exemplo para simulações, oito estruturas de pavimento com revestimento primário, as quais foram estudadas por Nervis (2016), Nervis (2010) e Peraça (2007). 0 objetivo desse processo foi o de comparar os valores das tensões obtidos através da metodologia simplificada com aqueles obtidos por meio de análises mecanísticas, para então obter um indicativo sobre a possibilidade de emprego da metodologia simplificada.

O carregamento considerado nas referidas simulações foi o do eixo padrão do DNIT (eixo simples de rodas duplas - ESRD de 8,2 t) especificado na norma DNER-ME 024/94, resultando numa carga de 2,05 t ou 20,5 kN por roda e na geometria de carregamento ilustrada na Figura 5. A pressão de inflação dos pneus foi considerada constante e igual a 0,56 MPa. As posições analisadas foram aquelas correspondentes aos alinhamentos verticais situados sob os pontos $\mathrm{X}_{1}$ (sob uma das rodas) e $\mathrm{X}_{2}$ (posição intermediária entre as rodas) representadas na Figura 5, nos pontos médios das camadas de revestimento primário e no topo do subleito. Foram efetuadas duas análises, sendo numa delas desprezado o efeito das cargas dinâmicas e na outra introduzida a conversão sugerida na Equação 14. Para tal, foi considerado um valor de $\mathrm{N}$ (calculado com os valores de equivalência da AASHTO) de $2 \times 10^{4}$. Esse valor foi adotado tomando como base uma estrada de baixo volume de tráfego com pavimento em revestimento primário referente a um estudo publicado por Nervis (2016), sendo considerado um período de projeto de 10 anos. 0 valor obtido dessa forma para a carga axial estática equivalente ( $\left.\mathrm{P}_{\mathrm{S}}\right)$, definida na Equação 14, foi de $243,787 \mathrm{kN}$.

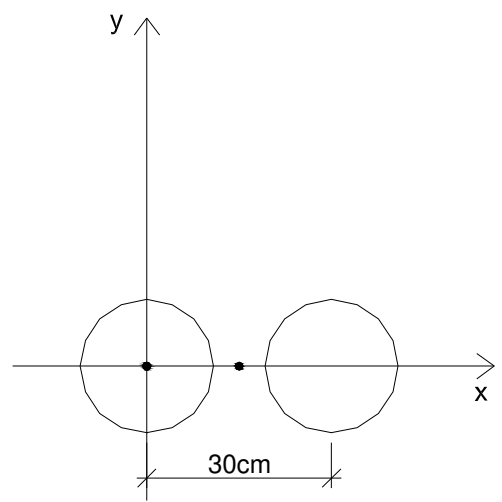

Figura 5: Esquema ilustrativo da geometria do carregamento (vista superior)

Nas simulações pela metodologia simplificada, considerou-se a superposição dos efeitos, tendo em vista que se trata de duas placas circulares carregadas gerando tensões nos pontos dos alinhamentos verticais situados sob $\mathrm{X}_{1}$ e $\mathrm{X}_{2}$.

Para a realização das análises mecanísticas foi empregado o software EVERSTRESS 5.0 desenvolvido pelo Departamento de Estradas de Rodagem do Estado de Washington (EUA). A estrutura analisada é caracterizada pela espessura das camadas, pelos módulos de resiliência, coeficientes de Poisson (v) e peso específico $(\gamma)$. São fornecidas as opções de considerar as interfaces das camadas plenamente aderidas entre si, parcialmente aderidas ou deslizantes, sendo neste trabalho considerada a primeira opção.

Nas Tabelas 3 e 4 são apresentados os resultados obtidos. Nos gráficos das Figuras 6 e 7 foram plotados os valores das tensões obtidos pela metodologia simplificada versus aqueles obtidos pela análise mecanística. 
Tabela 3: Simulações de obtenção de $\sigma_{1}$ e $\sigma_{3}$ através de análise mecanística e pela metodologia simplificada (sem considerar o efeito das cargas dinâmicas)

\begin{tabular}{|c|c|c|c|c|c|c|c|c|c|c|c|c|c|c|c|}
\hline \multirow{4}{*}{ 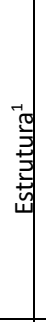 } & \multirow{4}{*}{ 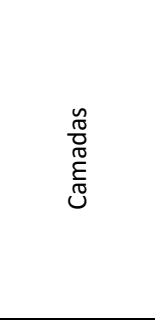 } & \multirow{4}{*}{ 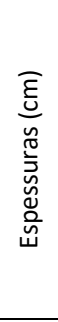 } & \multirow{4}{*}{ 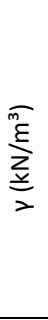 } & \multirow{4}{*}{$\cong$} & \multirow{4}{*}{$\stackrel{m}{\stackrel{m}{\Sigma}} \stackrel{\overparen{\pi}}{\sum}$} & \multicolumn{10}{|c|}{$\sigma_{1}$ e $\sigma_{3}$ obtidos $(\mathrm{kPa})^{4}$} \\
\hline & & & & & & \multicolumn{5}{|c|}{$\begin{array}{l}\text { Pontos sob a roda(posição } \mathrm{X}_{1} \mathrm{da} \\
\text { Figura } 6 \text { ) }\end{array}$} & \multicolumn{5}{|c|}{$\begin{array}{c}\text { Pontos intermediários } \\
\text { (posição } X_{2} \text { da Figura 6) }\end{array}$} \\
\hline & & & & & & \multirow[t]{2}{*}{ 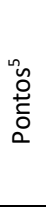 } & \multicolumn{2}{|c|}{ 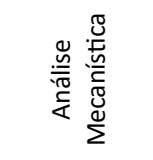 } & \multicolumn{2}{|c|}{$\begin{array}{l}\frac{\pi}{00} \frac{\pi}{0} \\
\frac{0}{0} \\
\frac{0}{0} \\
\frac{0}{0} \\
0 \\
\frac{0}{0} \\
\sum \frac{E}{2}\end{array}$} & \multirow[t]{2}{*}{ 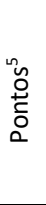 } & \multicolumn{2}{|c|}{ 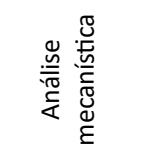 } & \multicolumn{2}{|c|}{$\begin{array}{l}\frac{\pi}{00} \frac{\pi}{0} \\
\frac{0}{0} \\
\frac{0}{0} \\
\frac{0}{0} \\
\frac{0}{0} \\
\stackrel{0}{0} \frac{E}{n} \\
\sum\end{array}$} \\
\hline & & & & & & & $\sigma_{1}$ & $\sigma_{3}$ & $\sigma_{1}$ & $\sigma_{3}$ & & $\sigma_{1}$ & $\sigma_{3}$ & $\sigma_{1}$ & $\sigma_{3}$ \\
\hline \multirow{4}{*}{1} & Saibro & 7,3 & 21 & 0,35 & $\left(p_{a t m}\right)$ & $\mathrm{P}_{1}$ & 531 & 215 & 542 & 248 & $P_{1}^{\prime}$ & 166 & 43 & 180 & 67 \\
\hline & $\begin{array}{l}\text { Argila } \\
\text { siltosa }\end{array}$ & 17,5 & 20 & 0,45 & $64,71\left(\frac{\sigma_{d}}{p}\right)$ & $\mathrm{P}_{2}$ & 251 & 20 & 256 & 20 & $\mathrm{P}_{2}^{\prime}$ & 186 & 13 & 179 & 11 \\
\hline & Areia siltosa ${ }^{6}$ & 15,0 & 21 & 0,35 & $39,07\left(\frac{\sigma}{p_{a t m}}\right)$ & $P_{S}$ & 153 & 3 & 153 & -1 & $\mathrm{Ps}_{\mathrm{s}}^{\prime}$ & 152 & 4 & 142 & -1 \\
\hline & Várias $^{7}$ & - & 21 & 0,40 & 256 & & & & & & & & & & \\
\hline \multirow[b]{2}{*}{2} & Areia argilosa & 7,5 & 21 & 0,45 & 105,4 & $\mathrm{P}_{1}$ & 522 & 266 & 541 & 277 & $\mathrm{P}_{1}^{\prime}$ & 232 & 58 & 223 & 60 \\
\hline & $\begin{array}{c}\text { Areia } \\
\text { (subleito) } \\
\end{array}$ & - & 21 & 0,45 & 62,4 & $\mathrm{P}_{\mathrm{S}}$ & 427 & 116 & 435 & 122 & $\mathrm{Ps}_{\mathrm{s}}^{\prime}$ & 202 & 50 & 207 & 42 \\
\hline \multirow[b]{2}{*}{3} & Areia argilosa & 25 & 21 & 0,45 & 105,4 & $\mathrm{P}_{1}$ & 315 & 38 & 329 & 41 & $\mathrm{P}_{1}^{\prime}$ & 175 & 19 & 186 & 21 \\
\hline & $\begin{array}{c}\text { Areia } \\
\text { (subleito) }\end{array}$ & - & 21 & 0,45 & 62,4 & $P_{S}$ & 129 & 6 & 151 & 4 & $P_{s}^{\prime}$ & 125 & 6 & 142 & 4 \\
\hline \multirow[b]{2}{*}{4} & Solo-agregado & 20 & 21 & 0,40 & 228 & $\mathrm{P}_{1}$ & 356 & 50 & 384 & 59 & $\mathrm{P}_{1}^{\prime}$ & 151 & 18 & 177 & 30 \\
\hline & $\begin{array}{c}\text { Areia } \\
\text { (subleito) }\end{array}$ & - & 21 & 0,45 & 62,4 & $P_{S}$ & 135 & 16 & 198 & 9 & $P_{s}^{\prime}$ & 125 & 17 & 161 & 7 \\
\hline \multirow{2}{*}{5} & $\begin{array}{l}\text { Pedregulho } \\
\text { arenoso }\end{array}$ & 15 & 19 & 0,35 & $34,35\left(\frac{\theta}{p_{g t m}}\right)$ & $\mathrm{P}_{1}$ & 451 & 93 & 459 & 99 & $P_{1}^{\prime}$ & 175 & 32 & 179 & 42 \\
\hline & $\begin{array}{l}\text { Subleito } \\
\text { argiloso }\end{array}$ & - & 19 & 0,45 & 50 & $P_{S}$ & 262 & 43 & 276 & 25 & $P_{s}^{\prime}$ & 184 & 34 & 188 & 15 \\
\hline \multirow[t]{2}{*}{6} & $\begin{array}{l}\text { Pedregulho } \\
\text { arenoso }\end{array}$ & 15 & 19 & 0,35 & $34,35\left(\frac{}{p_{a t m}}\right)$ & $\mathrm{P}_{1}$ & 469 & 95 & 459 & 99 & $P_{1}^{\prime}$ & 178 & 31 & 179 & 42 \\
\hline & $\begin{array}{l}\text { Subleito } \\
\text { argiloso }\end{array}$ & - & 19 & 0,45 & 150 & $P_{S}$ & 295 & 52 & 276 & 25 & $P_{s}^{\prime}$ & 190 & 37 & 188 & 15 \\
\hline \multirow[t]{2}{*}{7} & $\begin{array}{c}\text { Areia } \\
\text { pedregulhosa }\end{array}$ & 15 & 19 & 0,35 & $29,68\left(\frac{\theta}{p_{a t m}}\right)$ & $P_{1}$ & 454 & 93 & 459 & 99 & $P_{1}^{\prime}$ & 175 & 32 & 179 & 42 \\
\hline & $\begin{array}{l}\text { Subleito } \\
\text { argiloso }\end{array}$ & - & 19 & 0,45 & 50 & $P_{S}$ & 268 & 45 & 276 & 25 & $P_{s}^{\prime}$ & 185 & 35 & 188 & 15 \\
\hline \multirow{2}{*}{8} & $\begin{array}{c}\text { Areia } \\
\text { pedregulhosa }\end{array}$ & 15 & 19 & 0,35 & $29,68\left(\frac{v}{p}\right)$ & $P_{1}$ & 473 & 95 & 459 & 99 & $\mathrm{P}_{1}^{\prime}$ & 179 & 30 & 179 & 42 \\
\hline & $\begin{array}{l}\text { Subleito } \\
\text { argiloso }\end{array}$ & - & 19 & 0,45 & 150 & $P_{S}$ & 302 & 55 & 276 & 25 & $\mathrm{Ps}^{\prime}$ & 192 & 39 & 188 & 15 \\
\hline
\end{tabular}

${ }^{1}$ Estrutura 1 (NERVIS, 2016), Estruturas 2 a 4 (NERVIS, 2010) e Estruturas 5 a 8 (PERAÇA, 2007);

${ }^{2}$ No cálculo pela metodologia simplificada, adotou-se a média ponderada dos valores;

${ }^{2} N o$ cálculo pela metodologia simplificada, adotou-se a média ponderada
${ }^{3} \theta$ : somatório das tensões; $\sigma_{d}$ : tensão desvio e patm: pressão atmosférica;

${ }^{4}$ Convenção adotada: valores positivos para tensões de compressão e negativos para tensões de tração;

${ }^{5} \mathrm{P}_{1}$ e $\mathrm{P}_{1}{ }^{\prime}$ : pontos no meio da camada superior de revestimento primário;

$\mathrm{P}_{2}$ e $\mathrm{P}_{2}^{\prime}$ : pontos no meio da camada inferior de revestimento primário;

$P_{s}$ e $P_{s}^{\prime}$ : pontos no topo do subleito;

${ }^{6}$ Camada superior do subleito;

${ }^{7}$ Camadas inferiores do subleito. 
Tabela 4: Simulações de obtenção de $\sigma_{1}$ e $\sigma_{3}$ através de análise mecanística e pela metodologia simplificada (considerando o efeito das cargas dinâmicas)

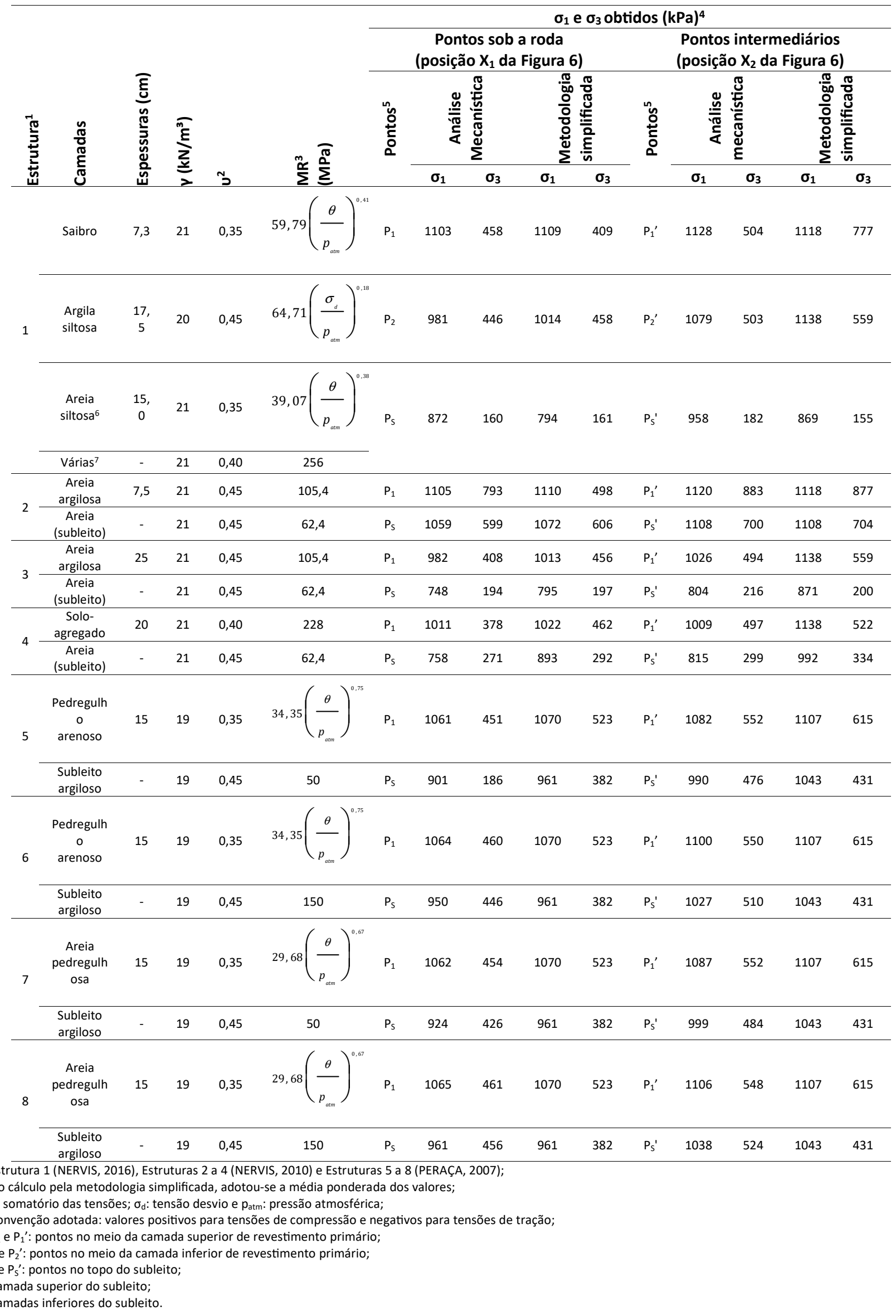




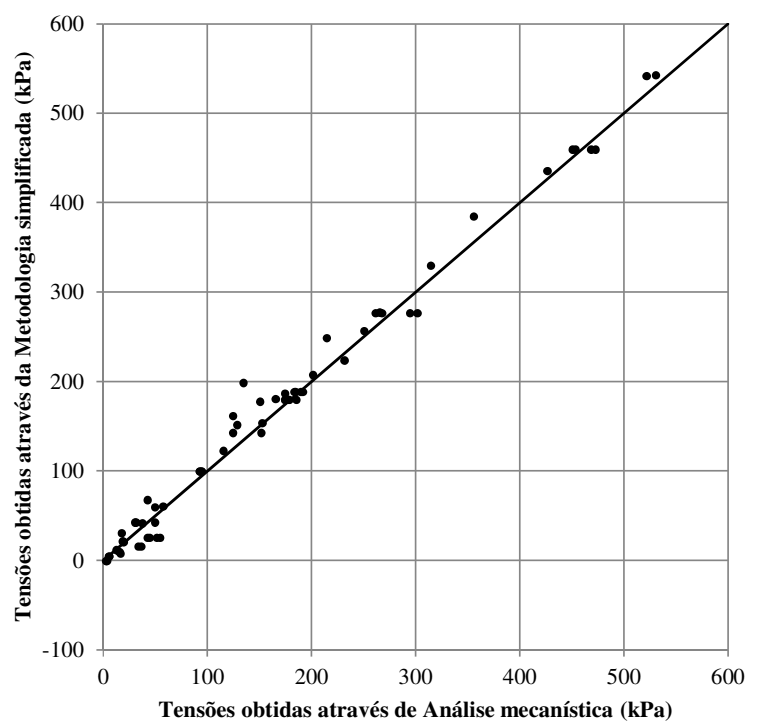

Figura 6: Valores das tensões obtidas pela metodologia simplificada versus aqueles obtidos pela análise mecanística (sem considerar o efeito das cargas dinâmicas)

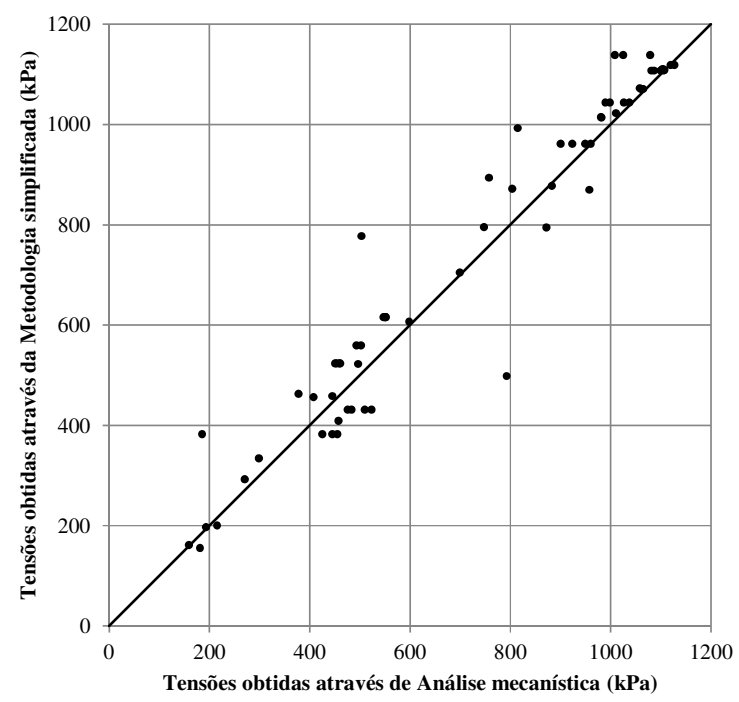

Figura 7: Valores das tensões obtidas pela metodologia simplificada versus aqueles obtidos pela análise mecanística (considerando o efeito das cargas dinâmicas)

Nos gráficos das Figuras 6 e 7, tem-se que quanto mais próximos os pontos se situam da reta de coeficiente angular igual a 1, maior é a similaridade entre os valores das tensões obtidos pela análise mecanística e pela metodologia simplificada. Uma correlação perfeita seria se todos os pontos se localizassem sobre essa reta, o que significaria que os valores obtidos por ambas as metodologias seriam iguais. Observa-se que isso não ocorre, porém, visualmente constata-se que as diferenças não são tão expressivas. Para melhor avaliar isso, realizou-se uma análise estatística que abrangeu dois procedimentos. 0 primeiro deles consistiu em verificar o nível de correlação entre os dois conjuntos de valores (obtidos por cada metodologia) através do cálculo do coeficiente de correlação linear de Pearson (r). Quanto mais próximo de 1 for o valor de $\mathrm{r}$, maior é a correlação. 0 segundo envolveu um teste paramétrico, com nível de significância de $5 \%$, no qual se considerou como hipótese $\mathrm{H}_{\mathrm{o}}$ que os valores seriam iguais e a hipótese $\mathrm{H}_{1}$ que os valores seriam diferentes.

A obtenção de valores do coeficiente de correlação linear de Pearson (r) de 0,99 e 0,97, para os dados das Tabelas 3 e 4, respectivamente, apontaram a existência de uma correlação linear positiva forte entre os valores das tensões obtidos pelas duas metodologias distintas. Os resultados dos testes paramétricos conduziram a aceitação das hipóteses $\mathrm{H}_{0}$, o que significa que não existe diferença significativa entre os 
valores. Isso fornece um indicativo de ser possível o emprego da metodologia simplificada para obtenção das tensões para pavimentos com revestimento primário nos pontos considerados, pois a margem de erro tende a ser bastante reduzida, frente a outras incertezas e fatores envolvidos, tais como os relacionados à obtenção dos parâmetros de resistência, heterogeneidade dos materiais e da compactação ao longo dos trechos, valores dos coeficientes de Poisson adotados, variações dos carregamentos e variações das espessuras das camadas.

\section{CONSIDERAÇÃO SOBRE A RESISTÊNCIA AO CISALHAMENTO DAS CAMADAS}

Para o emprego da metodologia simplificada para o dimensionamento de pavimentos com revestimento primário proposta neste artigo se faz necessário conhecer a envoltória de ruptura de Mohr-Coulomb da(s) camada(s) de revestimento e do subleito. Tal envoltória pode ser obtida experimentalmente através de ensaios triaxiais convencionais ou de cisalhamento direto, por exemplo.

Levando-se em consideração que o presente trabalho tem como contribuição trazer uma proposta para o dimensionamento de pavimentos com revestimento primário baseada em processos simplificados, de forma a tornar o seu emprego mais atrativo, sem, entretanto, perder o embasamento racional, admite-se também uma simplificação na obtenção dos parâmetros de resistência dos materiais (c e ø). Assim, sugere-se como alternativa a obtenção da envoltória de Mohr-Coulomb a partir da resistência à compressão simples $\left(\sigma_{c}\right)$ e da resistência à tração $\left(\sigma_{t}\right)$ do material. Para tal, são realizados, respectivamente, ensaios de compressão simples e de compressão diametral.

De acordo com Jaeger, Cook e Zimmerman (2007), as tensões principais na ruptura ( $\sigma_{3}$ e $\sigma_{1}$ ) para corpos de prova submetidos aos ensaios de compressão simples são, respectivamente, iguais a zero e $\sigma_{\mathrm{c}}$. Já para corpos de prova submetidos aos ensaios de compressão diametral, são, respectivamente, iguais a $\sigma_{\mathrm{t}} \mathrm{e}-3 \sigma_{\mathrm{t}}$. A partir disso, é possível plotar os círculos de Mohr correspondentes e então obter a envoltória de ruptura de Mohr-Coulumb (Figura 8), de onde são deduzidas as Equações 28 e 29.

$$
\begin{gathered}
\varnothing=\operatorname{arcsen}\left(\frac{\sigma_{\mathrm{c}}-4 \sigma_{\mathrm{t}}}{\sigma_{\mathrm{c}}-2 \sigma_{\mathrm{t}}}\right) \\
c=\frac{\sigma_{c}\left[1-\left(\frac{\sigma_{c}-4 \sigma_{t}}{\sigma_{c}-2 \sigma_{t}}\right)\right]}{2 \cos \varnothing}
\end{gathered}
$$

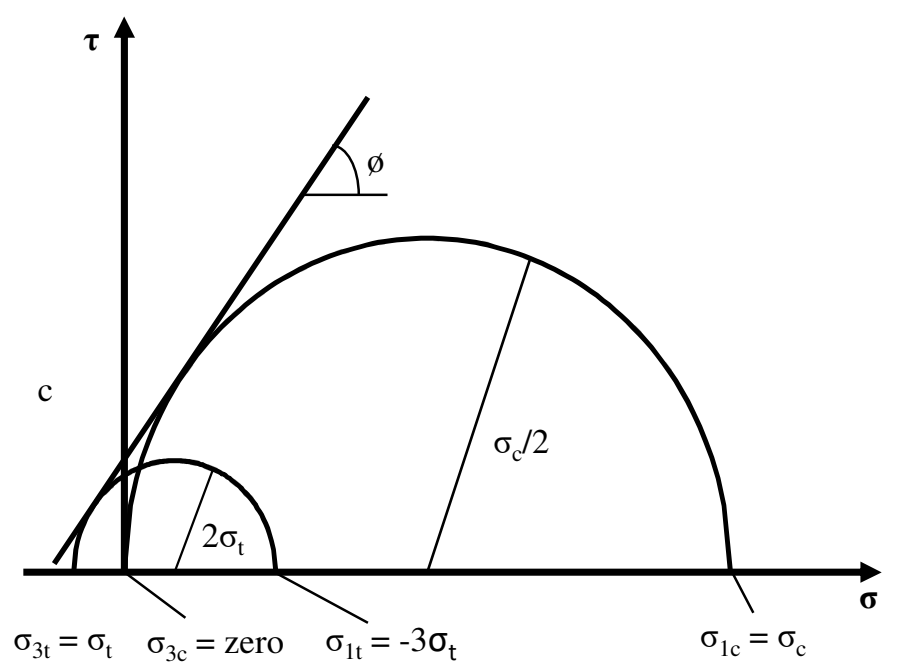

Figura 8: Envoltória de Mohr-Coulomb baseada em círculos de Mohr correspondentes aos ensaios de compressão simples e compressão diametral (CONSOLI et al., 2014)

O ensaio de compressão diametral foi desenvolvido inicialmente para a determinação da resistência à tração de corpos de prova de concreto. Mais tarde, de acordo com Medina (1997), foi introduzida a sua 
utilização em corpos de prova compactados de solos. Na literatura são encontrados vários trabalhos que registram a realização desse ensaio em corpos de prova de solos ou de solos tratados, como por exemplo nas publicações de Muntohar (2011), Consoli (2013), Consoli et. al (2014), Oliveira et al. (2015) e Silva et al. (2016).

Conforme a norma ABNT NBR 7222:1994, a partir do resultado do ensaio de compressão diametral, a resistência à tração $\left(\sigma_{t}\right)$ é calculada através da Equação 30.

onde:

$$
\sigma_{t}=\frac{2 F}{\pi D l}
$$

F: carga aplicada;

D: diâmetro do corpo de prova;

l: comprimento do corpo de prova.

Com o propósito de testar a acurácia da metodologia alternativa de obtenção da envoltória de ruptura a partir dos resultados de ensaios de compressão simples e de compressão diametral, Consoli (2013) tomou uma série de resultados experimentais de corpos de prova de areia fina tratada com cimento e areia siltosa tratada com cimento submetidos a esses ensaios e a ensaios triaxiais e a aplicou. Consoli et. al (2014) realizaram esse procedimento tomando uma série de resultados experimentais de corpos de prova de areia argilosa tratada com cal. Em ambos os trabalhos, os autores demonstraram e concluíram que, para os dados experimentais considerados, a metodologia alternativa se mostrou eficiente para a obtenção da envoltória de Mohr-Coulomb.

Ressalta-se que para muitos materiais granulares, devido à ausência de aspecto coesivo, não é possível a realização dos ensaios de compressão simples e de compressão diametral, inviabilizando nesses casos a aplicação da metodologia alternativa para a obtenção da envoltória de ruptura de Mohr-Coulomb apresentada neste tópico.

\section{EXEMPLO DE DIMENSIONAMENTO DE PAVIMENTO COM REVESTIMENTO PRIMÁRIO UTILIZANDO A PROPOSTA DE METODOLOGIA SIMPLIFICADA}

Com a finalidade de testar a metodologia proposta no presente trabalho, procedeu-se o dimensionamento para um exemplo de pavimento com revestimento primário aplicando-se e confrontando-se os resultados com aqueles obtidos a partir das propostas encontradas na literatura apresentadas no item 2 , para as quais também foram realizados os respectivos dimensionamentos.

Os materiais utilizados no presente exemplo foram aqueles estudados no trabalho publicado por Nervis (2016). Suas principais caraterísticas são apresentadas na Tabela 5. Trata-se de um pavimento com duas camadas de revestimento primário, sendo a inferior constituída de uma argila pertencente ao grupo LG' da classificação MCT. De acordo com os estudos publicados pelo autor, esse material se mostrou apropriado para emprego em revestimento primário, não podendo, entretanto, compor a camada de rolamento, devido a sua deficiência de aderência quando a pista estiver molhada. Assim, surge a demanda de uma camada superior para a correção de aderência, que no caso se constitui de um pedregulho arenoso (saibro), com finos de classificação MCT NA'. Segundo os estudos do autor, esse material, devido às suas caraterísticas, é inadequado para emprego em camadas mais espessas, servindo apenas para emprego em camadas mais esbeltas de modo a propiciar correção de aderência. No presente dimensionamento, a espessura da camada composta desse material foi fixada em $5 \mathrm{~cm}$.

Considerou-se a compactação das camadas na umidade ótima, com o emprego de rolo tipo pé-decarneiro para a camada de argila e de rolo liso para a camada de saibro. 0 carregamento considerado foi o mesmo adotado no item 4, assim como o valor de $\mathrm{N}$ e o período de projeto de 10 anos. 0 número estimado de passagens diárias de caminhões pesados foi inferior a 5. Para a obtenção das tensões através de análise mecanística foi empregado o software EVERSTRESS 5.0. Na Tabela 6 são apresentados os resultados obtidos. 
Tabela 5: Características dos materiais empregados no exemplo de dimensionamento. Fonte: Nervis, 2016

\begin{tabular}{|c|c|c|c|c|c|c|}
\hline \multirow{2}{*}{\multicolumn{3}{|c|}{ Propriedades }} & \multicolumn{3}{|c|}{ Materiais } & \multirow[b]{2}{*}{$\begin{array}{l}\text { Saibro } \\
\text { (camada superior } \\
\text { do revestimento) }\end{array}$} \\
\hline & & & $\begin{array}{l}\text { Camadas } \\
\text { inferiores } \\
\text { do } \\
\text { subleito }\end{array}$ & $\begin{array}{l}\text { Solo do Subleito } \\
\text { (espessura de } \\
30 \mathrm{~cm} \text { ) }\end{array}$ & $\begin{array}{l}\text { Argila } \\
\text { (camada inferior } \\
\text { do revestimento) }\end{array}$ & \\
\hline \multicolumn{3}{|c|}{ Classificação granulométrica segundo a NBR 6502: 95} & - & Areia siltosa & Argila siltosa & $\begin{array}{l}\text { Pedregulho } \\
\text { arenoso }\end{array}$ \\
\hline \multicolumn{3}{|c|}{ Classificação SUCS } & - & $M L$ & $\mathrm{CL}$ & SM \\
\hline \multicolumn{3}{|c|}{ Classificação da AASHTO } & - & A-4 & A-7-6 & A-2-4 \\
\hline \multicolumn{3}{|c|}{ Classificação MCT } & - & $\mathrm{NA}^{\prime}$ & $\mathrm{LG}^{\prime}$ & $\mathrm{NA}^{\prime}$ \\
\hline \multicolumn{3}{|c|}{ Peso específico $\left(\mathrm{kN} / \mathrm{m}^{3}\right)$} & 21 & 21 & 20 & 21 \\
\hline \multicolumn{3}{|c|}{ ISC ou CBR } & - & $19 \%$ & $14 \%$ & $8 \%$ \\
\hline \multicolumn{3}{|c|}{ Módulo de resiliência (MR) } & 256 & $\mathrm{MR}=39,07\left(\frac{\theta}{\mathrm{p}_{\text {atm }}}\right)^{0,38}$ & $M R=64,71\left(\frac{\sigma_{d}}{p}\right.$ & $M R=59,79\left(\frac{\theta}{p}\right)^{0,4}$ \\
\hline \multicolumn{3}{|c|}{ Coeficiente de Poisson } & 0,40 & 0,35 & 0,45 & 0,35 \\
\hline \multirow{6}{*}{$\begin{array}{l}\text { Parâmetros de } \\
\text { resistência ao } \\
\text { cisalhamento }\end{array}$} & \multirow{3}{*}{ Situação $1^{1}$} & $\psi^{2}(\mathrm{kPa})$ & - & 700,0 & 250,0 & 11,0 \\
\hline & & $\mathrm{c}^{2}(\mathrm{kPa})$ & - & 198 & 68 & 108 \\
\hline & & $\emptyset^{2}\left({ }^{\circ}\right)$ & - & 37 & 37 & 44 \\
\hline & \multirow{3}{*}{ Situação $2^{1}$} & $\Psi^{2}(\mathrm{kPa})$ & - & 3,5 & 4,0 & 0 \\
\hline & & $\mathrm{c}^{2}(\mathrm{kPa})$ & - & 16 & 33 & 74 \\
\hline & & $\phi^{2}\left({ }^{\circ}\right)$ & - & 37 & 37 & 44 \\
\hline
\end{tabular}

${ }^{1}$ Situação 1: teor de umidade da camada correspondente à ótima de compactação, considerando-se que assim ela foi compactada, mantendo-se nessas condições, ou seja, sem ocorrência de variações de umidade.

Situação 2: teor de umidade da camada correspondente à ótima de compactação, mas considerando-se que ela foi assim compactada, porém sofreu ciclos de secagem e umedecimento, retornando ao referido teor de umidade.

${ }^{2} \Psi$, c e $\varnothing$ : sucção mátrica, coesão e ângulo de atrito interno, respectivamente.

Tabela 6: Resultados do exemplo de dimensionamento de pavimento com revestimento primário

\begin{tabular}{|c|c|c|c|c|}
\hline \multirow{2}{*}{\multicolumn{3}{|c|}{ Métodos }} & \multicolumn{2}{|c|}{ Espessuras (cm) } \\
\hline & & & $\begin{array}{l}\text { Argila } \\
\text { (camada inferior do } \\
\text { revestimento) }\end{array}$ & $\begin{array}{l}\text { Saibro } \\
\text { (camada superior do } \\
\text { revestimento) }\end{array}$ \\
\hline \multicolumn{3}{|c|}{ Especificação do Estado de Dakota do Sul (descrita no item 2.1) } & 7 & 5 \\
\hline \multicolumn{3}{|c|}{ Especificação da República da África do Sul (descrita no item 2.2) } & 7 & 5 \\
\hline \multicolumn{3}{|c|}{ Método do DNER (descrita no item 2.3) } & 18 & 5 \\
\hline \multirow{4}{*}{$\begin{array}{l}\text { Modelo de Vésic } \\
\text { (descrito no item 2.4) }\end{array}$} & \multirow[b]{2}{*}{ Situação $1^{1}$} & $\begin{array}{l}\text { Tensões obtidas por análise } \\
\text { mecanística }\end{array}$ & 0 & 0 \\
\hline & & $\begin{array}{l}\text { Tensões obtidas pela } \\
\text { metodologia simplificada } \\
\text { apresentada no item } 4\end{array}$ & 0 & 0 \\
\hline & \multirow[b]{2}{*}{ Situação $2^{1}$} & $\begin{array}{l}\text { Tensões obtidas por análise } \\
\text { mecanística }\end{array}$ & 17 & 5 \\
\hline & & $\begin{array}{l}\text { Tensões obtidas pela } \\
\text { metodologia simplificada } \\
\text { apresentada no item } 4\end{array}$ & 15 & 5 \\
\hline \multirow{3}{*}{$\begin{array}{l}\text { Metodologia } \\
\text { simplificada proposta } \\
\text { no presente trabalho } \\
\text { (apresentada no item } \\
\text { 3.1) }\end{array}$} & \multirow[b]{2}{*}{ Situação $1^{1}$} & $\begin{array}{l}\text { Tensões obtidas por análise } \\
\text { mecanística }\end{array}$ & 13 & 5 \\
\hline & & $\begin{array}{l}\text { Tensões obtidas pela } \\
\text { metodologia simplificada } \\
\text { apresentada no item } 4\end{array}$ & 17 & 5 \\
\hline & Situação $2^{1}$ & $\begin{array}{l}\text { Tensões obtidas por análise } \\
\text { mecanística }\end{array}$ & 375 & 5 \\
\hline
\end{tabular}

${ }^{1}$ Situação 1: teor de umidade da camada correspondente à ótima de compactação, considerando-se que assim ela foi compactada, mantendo-se nessas condições, ou seja, sem ocorrência de variações de umidade.

Situação 2: teor de umidade da camada correspondente à ótima de compactação, mas considerando-se que ela foi assim compactada, porém sofreu ciclos de secagem e umedecimento, retornando ao referido teor de umidade.

Inicialmente, destaca-se que no trabalho publicado por Nervis (2016), foi monitorado durante 2,5 anos o desempenho de um trecho experimental de pavimento com revestimento primário construído 
com os materiais da Tabela 5, com espessuras da mesma ordem de grandeza das obtidas no dimensionamento pela Metodologia proposta no presente trabalho e com tensões obtidas pela metodologia simplificada apresentada no item 4 para a situação de umidade 1 (destacadas em negrito na Tabela 6). Os resultados demonstraram que na maior parte do trecho as deformações permanentes foram baixas, apontando que as espessuras empregadas foram adequadas. Justamente nos locais onde as deformações permanentes foram mais expressivas, se verificou que houve umedecimento ou umedecimento e secagem de uma ou mais camadas, prevalecendo, portanto, a situação 2 apresentada na Tabela 6. Isso fornece um indicativo que, para o exemplo apresentado, as metodologias propostas no presente trabalho apresentam potencial emprego, ponderando-se que o tempo de observação do desempenho do trecho experimental foi um tanto quanto limitado.

Do ponto de vista técnico, considerando-se a possibilidade de ocorrência de umedecimento e secagem das camadas, o ideal seria realizar o dimensionamento considerando a situação 2. Entretanto, conforme resultado apresentado na Tabela 6, o mesmo conduz a uma espessura considerável de $380 \mathrm{~cm}$ de revestimento primário, o que não se justifica economicamente. Assim, para o exemplo apresentado, se torna mais racional considerar a situação 1 e zelar pela implantação de sistemas de drenagem voltados a minimizar a variação de umidade das camadas. Nos locais onde não foi possível evitar tal variação, deve-se realizar manutenções periódicas, o que acaba gerando menos custos do que a execução do revestimento primário com espessura tão exagerada.

Os dimensionamentos realizados com o emprego das Especificações do Estado de Dakota do Sul e da República da África do Sul resultaram em espessuras de praticamente a metade das obtidas com a metodologia simplificada proposta no presente trabalho. Pelas baixas espessuras, provavelmente resultaria num pavimento de fraco desempenho.

As espessuras obtidas através do dimensionamento realizado empregando-se o método do DNER foram, para esse exemplo, da mesma ordem de grandeza obtida pela metodologia simplificada apresentada no presente trabalho. Cabe salientar, entretanto, que por se tratar de um método empírico, talvez isso não ocorra para outros casos, tendo em vista também que o CBR pode não apresentar correlação com a resistência ao cisalhamento das camadas, principalmente para tráfegos mais altos.

0 emprego do modelo de Vésic, embora também tenha natureza analítica, conduziu a espessuras muito menores do que as obtidas pela metodologia simplificada proposta neste trabalho, inclusive iguais a zero para a situação 1 descrita anteriormente. 0 referido modelo considera uma ruptura geral de uma porção do pavimento suposta rígida deslizando em relação a um maciço que permanece fixo através de uma superfície bem definida. Por outro lado, a metodologia simplificada, considera a mobilização da resistência ao cisalhamento em pontos das camadas, o que repercute, na prática, uma análise em termos de ruptura local. Para o exemplo aplicado, o emprego do modelo de Vésic se mostrou ineficiente. Entretanto, sugere-se, para o dimensionamento, o emprego tanto da metodologia simplificada quanto do modelo de Vésic, adotando-se para o projeto a solução que se mostrar mais robusta. Com isso, caso a ruptura geral se mostre prevalecente em relação à ruptura local, tem-se a garantia que tal situação não seja negligenciada.

\section{CONCLUSÕES}

A metodologia simplificada proposta neste trabalho, concebida a partir de conceitos da mecânica dos solos e mecânica dos pavimentos, se apresenta como uma alternativa de natureza analítica para o dimensionamento de pavimentos com revestimento primário, considerando a lacuna existente nesse assunto. Para um exemplo apresentado no presente trabalho, foi abstraído um indicativo positivo da validade de emprego dessa metodologia, tendo em vista que o desempenho observado de um trecho experimental com espessuras da mesma ordem de grandeza da obtida pelo dimensionamento foi satisfatório quando mantidas as mesmas condições de umidade.

Através de uma análise estatística, verificou-se para um conjunto de dados, que as simplificações sugeridas para a obtenção das tensões atuantes nos pontos médios das camadas de revestimento primário 
e no topo do subleito, podem ser empregadas, tendo em vista que as diferenças de valores em comparação àqueles obtidos através de análise mecanística são de uma ordem de grandeza aceitáveis. Assim, quando não se mostrarem a favor da segurança, as diferenças podem ser tranquilamente absorvidas pelo FS empregado.

No presente trabalho foi apresentada também uma metodologia alternativa de obtenção da envoltória de ruptura a partir dos resultados de ensaios de compressão simples e de compressão diametral. Foram encontrados na literatura dois trabalhos que testaram a acurácia da metodologia, porém para solos tratados com cal e tratados com cimento. Torna-se necessário confirmar a validade da metodologia para solos puros, embora ambos os ensaios já vem sendo realizados para solos com melhores propriedades e que apresentam uma certa coesão. Entretanto, vale ressaltar que para muitos materiais granulares, devido à ausência de aspecto coesivo, não é possível a realização dos ensaios de compressão simples e de compressão diametral, inviabilizando nesses casos a aplicação da referida metodologia alternativa.

Por fim, salienta-se que o emprego da presente proposta, demanda como parâmetros experimentais, somente a coesão e o ângulo de atrito das camadas, que podem ser obtidos a partir de ensaios triaxiais ou de cisalhamento direto, ou na forma mais simplificada, somente através dos ensaios de compressão simples e de compressão diametral. Isso torna mais atrativo o emprego do método, pois de nada adianta criar métodos que demandem como dados de entrada parâmetros obtidos a partir de ensaios de laboratório mais sofisticados se seu emprego esbarrar em custos e tempo desproporcionais para o tipo de via ou na dificuldade de encontrar laboratórios que os realizem.

\section{REFERÊNCIAS}

ABNT (1994) NBR 7222 - Concreto e argamassa — Determinação da resistência à tração por compressão diametral de corpos de prova cilíndricos. Associação Brasileira de Normas Técnicas, Rio de Janeiro.

American Association of State Highway and Transportation Officials - AASHTO (2008) Mechanistic-Empirical Pavement Design Guides - A manual of practice. AASHTO, Washington.

American Association of State Highway and Transportation Officials - AASHTO (2011) Guidelines for geometric design of very low-volume local roads. AASHTO, Washington.

Bernucci, L B. (1995) Considerações sobre o dimensionamento de pavimentos utilizando solos lateríticos para rodovias de baixo volume de tráfego. 237 f. Tese (Doutorado) - Escola Politécnica - USP, São Paulo. Disponível em: <http://www.teses.usp.br/teses/disponiveis/3/3138/tde-07042017-101955/pt-br.php>. (Acesso em: 16 jul. 2017).

Brasil (1994) Departamento Nacional de Estradas de Rodagem - DNER. Diretoria de Desenvolvimento Tecnológico. Instituto de Pesquisas Rodoviárias - IPR. Divisão de Capacitação Tecnológica. DNER-ME 024/94 Pavimento - Determinação das Deflexões pela Viga Benkelman. Instituto de Pesquisas Rodoviárias - IPR, Rio de Janeiro. Disponível em: <http://ipr.dnit.gov.br/normas-e-manuais/normas/meetodo-de-ensaio-me/dner-me024-94.pdf>. (Acesso em: 11 jul. 2017).

Brasil (2005) Departamento Nacional de Infraestrutura de Transportes - DNIT. Diretoria de Planejamento e Pesquisa. Coordenação Geral de Estudos e Pesquisas. Instituto de Pesquisas Rodoviárias - IPR. Manual de Conservação Rodoviária. Instituto de Pesquisas Rodoviárias - IPR, Rio de Janeiro. Disponível em:

<http://www1.dnit.gov.br/arquivos_internet/ipr/ipr_new/manuais/Manual\%20de\%20Conservacao\%20Rodoviaria.pdf >. (Acesso em: 11 jul. 2017).

Brasil (2006) Departamento Nacional de Infraestrutura de Transportes - DNIT. Diretoria de Planejamento e Pesquisa. Coordenação Geral de Estudos e Pesquisas. Instituto de Pesquisas Rodoviárias - IPR. Manual de Pavimentação Rodoviária. Instituto de Pesquisas Rodoviárias - IPR, Rio de Janeiro. Disponível em:

<https://www1.dnit.gov.br/arquivos_internet/ipr/ipr_new/manuais/Manual_de_Pavimentacao_Versao_Final.pdf >. (Acesso em: 15 jul. 2017).

Brasil (2016) Departamento Nacional de Infraestrutura de Transportes - DNIT. Divisão em Pavimentos do PNV 2016. Disponível em: < http://www.dnit.gov.br/sistema-nacional-de-viacao/sistema-nacional-de-viacao>. (Acesso em: 16 mar. 2017).

Consoli, N. C. (2013) A method proposed for the assessment of failure envelopes of cemented sandy soils. Engineering Geology, v. 169, p. 61-68. DOI: 10.1016/j.enggeo.2013.11.016

Consoli, N. C.; L. S. Lopes Jr; B. S. Consoli e L. Festugato (2014) Mohr-Coulomb failure envelopes of lime-treated soils. Géotechnique, v. 64, n. 2, p. 165-170. DOI: 10.1680/geot.12.P.168

Das, B. M. (2008) Advanced Soil Mechanics. Taylor \& Francis, New York.

Das, B. M. e K. SOBHAN (2014) Fundamentos de Engenharia Geotécnica. Cengage Learning, São Paulo.

Jaeger, J. C.; N. G. W. Cook e R. W. Zimmerman (2007) Fundamentals of rock mechanics. Blackwell Publishing, 4⿳亠丷a ed., Oxford. 
Keller, G. e J. Sherar (2003) Low-Volume Roads Engineering: Best Manegement Practices Field Guide. US Agency For International Development (USAID), Washington. Disponível em: <https://rosap.ntl.bts.gov/view/dot/34136>. (Acesso em: 19 abr. 2018).

Medina, J. (1997) Mecânica dos Pavimentos. UFRJ, 1aㅡ ed., Rio de Janeiro.

Medina, J. e L. M. G. Motta (2005) Mecânica dos Pavimentos. UFRJ, 2ª ed., Rio de Janeiro.

Muntohar, A. S. (2011). Effect of specimen size on the tensile strength behavior of the plastic waste fiber reinforced soil. Civil Engineering Dimension, v. 13, n. 2, p. 82-89. DOI: 10.9744/ced.13.2.82-89

Nervis, L. O. (2010) Estudo de revestimento primário para utilização em estradas vicinais da região de Santana do Livramento $R S .154$ f. Dissertação (Mestrado) - Programa de Pós Graduação em Engenharia Civil, Universidade Federal do Rio Grande do Sul - PPGEC/UFRGS, Porto Alegre. Disponível em: <http://www.lume.ufrgs.br/bitstream/handle/10183/28783/000772469.pdf?...1>. (Acesso em: 17 jul. 2017).

Nervis, L. O. (2016) Identificação e discussão dos mecanismos de degradação de pavimentos com revestimento primário. $271 \mathrm{f}$. Tese (Doutorado) - Programa de Pós Graduação em Engenharia Civil, Universidade Federal do Rio Grande do Sul PPGEC/UFRGS, Porto Alegre. Disponível em: <http://www.lume.ufrgs.br/handle/10183/143731>. (Acesso em: 16 mar. 2017).

Nogami, J. S. e D. F. Villibor. (1995) Pavimentação de Baixo Custo com Solos Lateríticos. Villibor, São Paulo.

Oliveira, P. J. V.; M. S. Costa; J. N. P. Costa e M. F. Nobre (2015). Comparison of ability of two bacteria to improve the behavior of sandy soil. J. Mater. Civ. Eng., v. 27, n. 1, p. 1-5. DOI: 10.1061/(ASCE)MT.1943-5533.0001138

Ollo, S. Y.; D. G. Fredlund e J. K. M. Gan (1997) Bearing capacity of unpaved roads. Canadian Geotechinal Journal, v. 34, p. 398407.

Paige-Green, P. (1990) Draft TRH 20 - The Structural Design, Construction and Maintenance of Unpaved Roads. Departament of Transport of the Republic South Africa, Pretoria. Disponível em: < http://www.nra.co.za/content/Blogin/22.pdf>. (Acesso em: 18 jul. 2017).

Paraná (2005) Departamento de Estradas de Rodagem do Estado do Paraná - DER/PR . DER/PR ES-T 07/05 Terraplenagem: Revestimento Primário. Departamento de Estradas de Rodagem do Estado do Paraná - DER/PR, Curitiba. Disponível em: <http://www.der.pr.gov.br/arquivos/File/PDF/pdf_Terraplenagem/ES-T07-05RevestimentoPrimario.pdf>. (Acesso em: 10 set. 2017).

Peraça, V. (2007) Qualificando Solos para Revestimento Primário de Rodovias: Uma Abordagem Baseada na Mecânica dos Solos e dos Pavimentos. 169 f. Dissertação (Mestrado) - Programa de Pós Graduação em Engenharia Civil, Universidade Federal do Rio Grande do Sul - PPGEC/UFRGS, Porto Alegre. Disponível em: <http:// http://www.lume.ufrgs.br/handle/10183/12550>. (Acesso em: 19 abr. 2018).

Skorseth, K. e A. Selim (2000) Gravel Roads: Maintenance and Design Manual. U.S. Department of Transportation. Federal Highway Administration - FHWA. South Dakota Local Transportation - SD LTAP. Disponível em: <http://www.nijc.org/pdfs/TTAP/gravelman.pdf>. (Acesso em: 15 jul. 2017).

Silva, A. M.; L. C. F. L. Lucena; A. E. F. L. Lucena; P. G. T. Marinho Filho; L. F. Costa e J. Ferreira (2016) Avaliação de um solo em termos de resistência à compressão simples, resistência à tração por compressão diametral e módulo de resiliência, considerando resultados de diferentes tipos de compactação. Anuário do Instituto de Geociências da UFRJ , v. 39, n. 3, p. 4147. DOI: $10.11137 / 2016 \_3 \_41 \_47$

Villibor, D. F., D. F. Nogami; J. R. Cincerre; P. R. M. Serra e A. Zuppolini Neto (2009) Pavimentos de baixo custo para vias urbanas. Arte \& Ciência, São Paulo. 


\section{ANEXOS}

(AHLVIN e ULERY, 1962 apud DAS, 2008).

\section{ANEXO 1: FUNÇÃO A}

\begin{tabular}{|c|c|c|c|c|c|c|c|c|c|c|c|c|c|c|c|c|c|c|}
\hline \multirow[t]{2}{*}{$\mathrm{z} / \mathrm{b}$} & \multicolumn{18}{|c|}{$s / b$} \\
\hline & 0 & 0.2 & 0.4 & 0.6 & 0.8 & 1 & 1.2 & 1.5 & 2 & 3 & 4 & 5 & 6 & 7 & 8 & 10 & 12 & 14 \\
\hline $0 \quad 1$. & 1.0 & 1.0 & 1.0 & 1.0 & 1.0 & .5 & 0 & 0 & 0 & 0 & 0 & 0 & 0 & 0 & 0 & 0 & 0 & 0 \\
\hline 0.1 . & .90050 & .89748 & .88679 & .86126 & .78797 & .43015 & .09645 & .02787 & .00856 & .00211 & .00084 & .00042 & & & & & & \\
\hline 0.2 & .80388 & В.79824 & .77884 & .73483 & .63014 & .38269 & 15433 & .05251 & .01680 & .00419 & .00167 & .00083 & .00048 & .00030 & .00020 & & & \\
\hline 0.3 & .71265 & 5.70518 & .68316 & .62690 & .52081 & .34375 & .17964 & .07199 & .02440 & .00622 & .00250 & & & & & & & \\
\hline 0.4 & .62861 & .62015 & .59241 & .53767 & .44329 & .31048 & 18709 & .08593 & .03118 & & & & & & & & & \\
\hline 0.5 & .55279 & 9.54403 & .51622 & .46448 & .38390 & .28156 & .18556 & .09499 & .03701 & .01013 & .00407 & .00209 & .00118 & .00071 & .00053 & .00025 & .00014 & .00009 \\
\hline 0.6 & .48550 & (4769I. & .45078 & .40427 & .33676 & .25588 & .17952 & .10010 & & & & & & & & & & \\
\hline 0.7 & .42654 & 4.41874 & .3949/ & .35428 & .29833 & .21727 & 17124 & .10228 & .04558 & & & & & & & & & \\
\hline 0.8 & .37531 & .36832 & .34729 & .31243 & .26581 & .21297 & 16206 & .10236 & & & & & & & & & & \\
\hline 0.9 & .33104 & 4. .32492 & .30669 & .27707 & .23832 & .19488 & .15253 & .10094 & & & & & & & & & & \\
\hline 1 & .29289 & 9. 28763 & .27005 & .24697 & .21468 & .17868 & 14329 & .09849 & .05185 & .01742 & .00761 & .00393 & .00226 & 6.00143 & .00097 & .00050 & .00029 & .00018 \\
\hline 1.2 & .23178 & 3. 22795 & .21662 & 19890 & .17626 & .15101 & .12570 & .09192 & .05260 & .01935 & .00871 & .00459 & .00269 & 9.00171 & .00115 & & & \\
\hline 1.5 & (16795 & 5.16552 & 15877 & .14804 & .13436 & .11892 & .10296 & .08048 & .05116 & .02142 & .01013 & .00548 & .00325 & .00210 & .00141 & .00073 & .00043 & .00027 \\
\hline 2 & . 10557 & .10453 & .10140 & .09647 & I.09011. & .08269 & .07471 & .06275 & .04496 & .02221 & .01160 & .00659 & .00399 & .00264 & .00180 & .00094 & & .00036 \\
\hline 2.5 & .07152 & 2.07098 & .06947 & .06698 & .06373 & .05974 & .05555 & .04880 & .03787 & .02143 & .01221 & .00732 & .00463 & .00308 & .00214 & .00115 & .00068 & .00043 \\
\hline 3 & .05132 & 2.05101 & .05022 & .04886 & .04707 & .04487 & .04241 & .03839 & .03150 & .01980 & .01220 & .00770 & .00505 & .00346 & .00242 & .00132 & .00079 & .00051 \\
\hline 4 & .02986 & 6.02976 & .02907 & .02802 & .02832 & .02749 & .02651 & .02490 & .02193 & .01592 & .01109 & .00768 & .00536 & .00384 & .00282 & .00160 & .00099 & .00065 \\
\hline 5 & .01942 & 2.01938 & & & & .01835 & & & .01573 & .01249 & .00949 & .00708 & .00527 & .00394 & .00298 & .00179 & .00113 & .00075 \\
\hline 6 & .01361 & & & & & .01307 & & & .01168 & .00983 & .00795 & .00628 & .00492 & .00384 & .00299 & .00188 & .00124 & .00084 \\
\hline 7 & .01005 & & & & & .00976 & & & .00894 & .00784 & .00661 & .00548 & .00445 & .00360 & .00291 & .00193 & .00130 & .00091 \\
\hline 8 & .00772 & & & & & .00755 & & & .00703 & .00635 & .00554 & .00472 & .00398 & .00332 & .00276 & .00189 & .00134 & .00094 \\
\hline 9 & .00612 & & & & & .00600 & & & .00566 & .00520 & .00466 & .00409 & .00353 & .00301 & .00256 & .00184 & .00133 & .00096 \\
\hline 10 & & & & & & & & .00477 & .00465 & .00438 & .00397 & .00352 & .00326 & .00273 & .00241 & & & \\
\hline
\end{tabular}

\section{ANEXO 2: FUNÇÃO B'}

\begin{tabular}{|c|c|c|c|c|c|c|c|c|c|c|c|c|c|c|c|c|c|c|}
\hline \multirow[t]{2}{*}{$z / b$} & \multicolumn{18}{|c|}{$s / b$} \\
\hline & 0 & 0.2 & 0.4 & 0.6 & 0.8 & 1 & 1.2 & 1.5 & 2 & 3 & 4 & 5 & 6 & 7 & 8 & 10 & 12 & 14 \\
\hline 0 & & 0 & 0 & 0 & 0 & 0 & 0 & 0 & 0 & 0 & 0 & 0 & 0 & 0 & 0 & 0 & 0 & 0 \\
\hline 0.1 & .09852 & .10140 & .11138 & 3.13424 & .18796 & $.05388-$ & -.07899 & $-.02672-$ & -.00845 & $-.00210-$ & -.00084 & -.00042 & & & & & & \\
\hline 0.2 & .18857 & .19306 & .20772 & 2.23524 & .25983 & $.08513-$ & $-.07759-$ & $-.04448-$ & -.01593 & $-.00412-$ & $-.00166-$ & -.00083 & $-.00024-$ & $-.00015-$ & -.00010 & & & \\
\hline 0.3 & .26362 & .26787 & .28018 & .29483 & .27257 & $.10757-$ & $-.04316-$ & $-.04999-$ & $-.02166-$ & $-.00599-$ & -.00245 & & & & & & & \\
\hline 0.4 & .32016 & .32259 & .32748 & 3. 32273 & .26925 & $5.12404-$ & $-.00766-$ & -.04535 & -.02522 & & & & & & & & & \\
\hline 0.5 & . 35777 & .35752 & .35323 & 3.33106 & .26236 & |.13591 & $.02165-$ & $-.03455-$ & $-.02651-$ & $|-.0099|-$ & $-.00388-$ & $-.00199-$ & $-.00116-$ & $-.00073-$ & -.00049 & $9-.00025$ & -.00014 & $t-.00009$ \\
\hline 0.6 & .37831 & .37531 & .36308 & .32822 & .25411 & . 14440 & $.04457-$ & -.02101 & & & & & & & & & & \\
\hline 0.7 & .38487 & .37962 & .36072 & . 31929 & .24638 & 14986. & .06209 & -.00702 & -.02329 & & & & & & & & & \\
\hline 0.8 & .38091 & .37408 & .35133 & 30699 & .23779 & .15292 & .07530 & .00614 & & & & & & & & & & \\
\hline 0.9 & .36962 & .36275 & .33734 & 29299 & .2289 & .15404 & .08507 & .01795 & & & & & & & & & & \\
\hline I & .35355 & .34553 & .32075 & 27819 & .21978 & .15355 & .09210 & .02814 & -.01005 & $-.01115-$ & $-.00608-$ & -.00344 & $-.00210-$. & $-.00135-$ & -.00092 & $2-.00048$ & $3-.00028$ & $3-.00018$ \\
\hline 1.2 & .31485 & .30730 & $.2848 \mid$ & .24836 & .20113 & .14915 & .10002 & .04378 & .00023 & $-.00995-$ & $-.00632-$ & $-.00378-$ & $-.00236-$ & $-.00156-$ & -.00107 & & & \\
\hline 1.5 & .25602 & .25025 & .23338 & .20694 & .17368 & .13732 & .10193 & .05745 & .01385 & $-.00669-$ & $-.00600-$ & $-.00401-$ & $-.00265-$ & $-.00181-$ & -.00126 & $6-.00068$ & $8-.00040$ & -.00026 \\
\hline 2 & . 17889 &.$|8| 44$ & .16644 & . 15198 & .13375 & .11331 & .09254 & .06371 & .02836 & $.00028-$ & $-.00410-$ & $-.00371-$ & $-.00278-$ & $-.00202-$ & -.00148 & $8-.00084$ & -.00050 & -.00033 \\
\hline 2.5 & 12807 & .12633 & .12126 & . 11327 & .10298 & .09130 & .07869 & .06022 & .03429 & $.00661-$ & $-.00130-$ & $-.00271-$ & $-.00250-$ & $-.00201-$ & -.00156 & $6-.00094$ & $1-.00059$ & -.00039 \\
\hline 3 & .09487 & .09394 & .09099 & .08635 & .08033 & .07325 & .06551 & .05354 & .03511 & .01112 & $.00157-$ & $-.00134-$ & $-.00192-$ & $-.00179-$ & -.00151 & $1-.00099$ & -.00065 & -.00046 \\
\hline 4 & .05707 & .05666 & .05562 & .05383 & .05145 & .04773 & .04532 & .03995 & .03066 & .01515 & .00595 & .00155 & $-.00029-$. & -.00094 & -.00109 & $9-.00094$ & -.00068 & $3-.00050$ \\
\hline 5 & .03772 & .03760 & & & & .03384 & & & .02474 & .01522 & .00810 & .00371 & .00132 & $.00013-$ & -.00043 & -.00070 & -.0006 & -.00049 \\
\hline 6 & .02666 & & & & & .02468 & & & .01968 & .01380 & .00867 & .00496 & .00254 & .00110 & .00028 & $8-.00037$ & -.00047 & $7-.00045$ \\
\hline 7 & .01980 & & & & & .01868 & & & .01577 & .01204 & .00842 & .00547 & .00332 & .00185 & .00093 & $3-.00002$ & & $9-.00037$ \\
\hline 8 & .01526 & & & & & .01459 & & & .01279 & .01034 & .00779 & .00554 & .00372 & .00236 & .00141 & .00035 & -.00008 & $3-.00025$ \\
\hline 9 & .01212 & & & & & .01170 & & & .01054 & .00888 & .00705 & .00533 & .00386 & .00265 & .00178 & 3.00066 & 5.00012 & $2-.00012$ \\
\hline 10 & & & & & & & & .00924 & .00879 & .00764 & .00631 & .00501 & .00382 & $.0028 \mathrm{I}$ & .00199 & & & \\
\hline
\end{tabular}

\section{ANEXO 3: FUNÇÃO C}

\begin{tabular}{|c|c|c|c|c|c|c|c|c|c|c|c|c|c|c|c|c|c|c|}
\hline \multirow[t]{2}{*}{$z / b$} & \multicolumn{18}{|c|}{$s / b$} \\
\hline & 0 & 0.2 & 0.4 & 0.6 & 0.8 & 1 & 1.2 & 1.5 & 2 & 3 & 4 & 5 & 6 & 7 & 8 & 10 & 12 & 14 \\
\hline 0 & 0 & 0 & 0 & 0 & 0 & 0 & 0 & 0 & 0 & 0 & 0 & 0 & 0 & 0 & 0 & 0 & 0 & 0 \\
\hline 0.1 & -.04926 & -.05142 & -.05903 & -.0770 & -.12108 & .02247 & .12007 & .04475 & .01536 & .00403 & .00164 & $4 \quad .00082$ & & & & & & \\
\hline 0.2 & -.09429 & -.09775 & -.10872 & -.1297 & -.14552 & .02419 & 14896 & .07892 & .02951 & .00796 & .00325 & .00164 & .00094 & .00059 & .00039 & & & \\
\hline 0.3 & -.13181 & -.13484 & -.14415 & -.1502 & -.12990 & .01988 & 13394 & .09816 & .04148 & .01169 & .00483 & & & & & & & \\
\hline 0.4 & -.16008 & -.16188 & -.16519 & -.1598 & -.11168 & .01292 & .11014 & .10422 & .05067 & & & & & & & & & \\
\hline 0.5 & -.17889 & -.17835 & -.17497 & -.1562 & -.09833 & .00483 & .08730 & .10125 & .05690 & .01824 & .00778 & .00399 & .00231 & .00146 & .00098 & .00050 & .00029 & .00018 \\
\hline 0.6 & -.18915 & -.18664 & -.17336 & -.1493 & -.08967 & -.00304 & .06731 & .09313 & & & & & & & & & & \\
\hline 0.7 & -.19244 & -.18831 & -.17393 & -.1414 & -.08409 & -.01061 & .05028 & .08253 & .06129 & & & & & & & & & \\
\hline 0.8 & -.19046 & -.18481 & -.16784 & -.1339 & -.08066 & -.01744 & .03582 & .07114 & & & & & & & & & & \\
\hline 0.9 & -.18481 & -.17841 & -.16024 & -.1266 & -.07828 & -.02337 & .02359 & .05993 & & & & & & & & & & \\
\hline 1 & -.17678 & -.17050 & -.15188 & -.1199 & -.07634 & -.02843 & .01331 & .04939 & .05429 & .02726 & .01333 & .00726 & .00433 & .00278 & .00188 & .00098 & .00057 & .00036 \\
\hline 1.2 & -.15742 & -.15117 & -.13467 & -.1076 & -.07289 & -.03575 & -.00245 & .03107 & .04552 & .02791 & .01467 & .00824 & .00501 & .00324 & .00221 & & & \\
\hline 1.5 & -.12801 & -.12277 & -.11101 & -.0914 & -.06711 & -.04124 & -.01702 & .01088 & .03154 & .02652 & .01570 & .00933 & .00585 & .00386 & .00266 & .00141 & .00083 & .00039 \\
\hline 2 & -.08944 & -.08491 & -.07976 & -.0692 & -.05560 & -.04144 & -.02687 & -.00782 & .01267 & .02070 & .01527 & .01013 & .00321 & .00462 & .00327 & .00179 & .00107 & .00069 \\
\hline 2.5 & -.06403 & -.06068 & -.05839 & -.0525 & -.04522 & -.03605 & -.02800 & -.01536 & .00103 & .01384 & .01314 & .00987 & .00707 & .00506 & .00369 & .00209 & .00128 & .00083 \\
\hline 3 & -.04744 & -.04560 & -.04339 & -.0408 & -.03642 & -.03130 & -.02587 & -.01748 & -.00528 & .00792 & .01030 & .00888 & .00689 & .00520 & .00392 & .00232 & .00145 & .00096 \\
\hline 4 & -.02854 & -.02737 & -.02562 & -.0258 & -.02421 & -.02112 & -.01964 & -.01586 & -.00956 & .00038 & .00492 & .00602 & .00561 & .00476 & .00389 & .00254 & .00168 & .00115 \\
\hline 5 & -.01886 & -.01810 & & & & -.01568 & & & -.00939 & -.00293 & -.00128 & .00329 & I.00391 & .00380 & .00341 & .00250 & .00177 & .00127 \\
\hline 6 & -.01333 & & & & & -.01118 & & & -.00819 & -.00405 & -.00079 & .00129 & .00234 & .00272 & .00272 & .00227 & .00173 & .00130 \\
\hline 7 & -.00990 & & & & & -.00902 & & & -.00678 & -.00417 & -.00180 & -.00004 & .00113 & .00174 & .00200 & .00193 & .00161 & .00128 \\
\hline 8 & -.00763 & & & & & -.00699 & & & -.00552 & -.00393 & -.00225 & -.00077 & .00029 & .00096 & .00134 & .00157 & .00143 & .00120 \\
\hline 9 & -.00607 & & & & & -.00423 & & & -.00452 & -.00353 & -.00235 & -.00118 & -.00027 & .00037 & .00082 & .00124 & .00122 & .00110 \\
\hline 10 & & & & & & & & -.00381 & -.00373 & -.00314 & -.00233 & -.00137 & -.00063 & .00030 & .00040 & & & \\
\hline
\end{tabular}




\section{ANEXO 4: FUNÇÃO D}

\begin{tabular}{|c|c|c|c|c|c|c|c|c|c|c|c|c|c|c|c|c|c|c|}
\hline \multirow[t]{2}{*}{$z / b$} & \multicolumn{18}{|c|}{$s / b$} \\
\hline & 0 & 0.2 & 0.4 & 0.6 & 0.8 & 1 & 1.2 & 1.5 & 2 & 3 & 4 & 5 & 6 & 7 & 8 & 10 & 12 & 14 \\
\hline $\begin{array}{ll}0 & 0\end{array}$ & & 0 & 0 & 0 & 0 & 0 & 0 & 0 & 0 & 0 & 0 & 0 & 0 & 0 & 0 & 0 & 0 & 0 \\
\hline 0.1 & .04926 & .04998 & .05235 & 5.05716 & .06687 & 7.07635 & .04108 & B. 01803 & I.00691 & 1.00193 & .00080 & 0.00041 & & & & & & \\
\hline 0.2 & .09429 & .09552 & .09900 & .10546 & $.1143 \mid$ & .10932 & .07139 & .03444 & $\begin{array}{l}4.01359 \\
\end{array}$ & 9.00384 & .00159 & 9.00081 & .00047 & 7.00029 & 9.00020 & & & \\
\hline 0.3 & $.1318 \mid$ & .13305 & .14051 & .14062 & 14267 & 7.12745 & .09078 & 8. 04817 & .01982 & 2.00927 & .00238 & & & & & & & \\
\hline 0.4 & .16008 & 3. 16070 & .16229 & .16288 & .15756 & 6.13696 & .10248 & .05887 & .02545 & & & & & & & & & \\
\hline 0.5 & .17889 & 9.17917 & .17826 & 6. & .16403 & 14074. & .10894 & 4.06670 & .03039 & 9.00921 & .00390 & 0.00200 & .00116 & 6.00073 & 3.00049 & 9.00025 & .00015 & 5.00009 \\
\hline 0.6 & .18915 & 18867 & .18573 & . 17887 & .16489 & 9.14137 & .11186 & 6.07212 & & & & & & & & & & \\
\hline 0.7 & .19244 & 4.19132 & .18679 & .17782 & .16229 & .13926 & .11237 & 7.07551 & .03801 & & & & & & & & & \\
\hline 0.8 & .19046 & 18927. & .18348 & 3. 3.17306 & .15714 & 4.13548 & .111115 & 5.07728 & & & & & & & & & & \\
\hline 0.9 & .18481 & .18349 & .17709 & .16635 & .15063 & 3.13067 & .10866 & 6.07788 & & & & & & & & & & \\
\hline I & .17678 & 3. 17503 & .16886 & .15824 & .14344 & 4.12513 & .10540 & .07753 & .04456 & 6.01611 & .00725 & 5.00382 & .00224 & 4.00142 & 2.00096 & 6.00050 & .00029 & 9.00018 \\
\hline 1.2 & 15742 & 15618 & .15014 & 4.14073 & .12823 & 3.11340 & 09757 & $7 \quad 07484$ & .04575 & $5 \quad 01796$ & .00835 & 5.00446 & 00264 & 4.00169 & 9.00114 & & & \\
\hline 1.5 & .12801 & .12754 & .12237 & .11549 & .10657 & 7.09608 & .0849 & .06833 & .04539 & 9.01983 & .00970 & 0.00532 & .00320 & 0.00205 & .00140 & 0.00073 & .00043 & 3.00027 \\
\hline 2 & .08944 & 4.09080 & .08668 & 3.08273 & .07814 & 4.07187 & .06566 & 6.05589 & .04103 & 3.02098 & .01117 & 7.00643 & .00398 & 8.00260 & .00179 & 9.00095 & .00056 & 6.00 \\
\hline 2.5 & .06403 & .06565 & .06284 & 4.06068 & .05777 & 7.05525 & .05069 & .04486 & .03532 & 2.02045 & .01183 & 3.00717 & .00457 & 7.00306 & 6.00213 & 3.00115 & .00068 & 8.00 \\
\hline 3 & .04744 & .04834 & .04760 & .04548 & .0439 & .04195 & .03963 & .03606 & .02983 & 3. 01904 & .01187 & 7.00755 & .00497 & 7.00341 & .00242 & 2.00133 & .00080 & 0.00052 \\
\hline 4 & .02854 & .02928 & .02996 & .02798 & .02724 & 4.02661 & .02568 & B. .02408 & .02110 & .01552 & .01087 & 7.00757 & .00533 & 3.00382 & 2.00280 & 0.00160 & .00100 & .00065 \\
\hline 5 & .01886 & .01950 & & & & .01816 & & & .01535 & 5.01230 & .00939 & 9.00700 & .00523 & 3.00392 & .00299 & & .00114 & 4.00077 \\
\hline 6 & .01333 & & & & & .01351 & & & .01149 & 9.00976 & .00788 & B. .00625 & .00488 & 8.00381 & .00301 & I. .00190 & .00 & 4.00086 \\
\hline 7 & .00990 & & & & & .00966 & & & .00899 & 9.00787 & .00662 & 2.00542 & .00445 & 5.00360 & .00292 & & & \\
\hline 8 & .00763 & & & & & .00759 & & & .00727 & 7.00641 & .00554 & 4.00477 & .00402 & 2.00332 & .00275 & & .00131 & I . 00096 \\
\hline 9 & .00607 & & & & & .00746 & & & .00601 & 1.00533 & .00470 & 0.00415 & .00358 & 8.00303 & .00260 & 0.00187 & .00133 & 3.00099 \\
\hline 10 & & & & & & & & .00542 & .00506 & 6.00450 & .00398 & 8. .00364 & .00319 & 9.00278 & .00239 & & & \\
\hline
\end{tabular}

\section{ANEXO 5: FUNÇÃO E}

\begin{tabular}{|c|c|c|c|c|c|c|c|c|c|c|c|c|c|c|c|c|c|c|}
\hline \multirow[t]{2}{*}{$z / b$} & \multicolumn{18}{|c|}{$s / b$} \\
\hline & 0 & 0.2 & 0.4 & 0.6 & 0.8 & I & 1.2 & 1.5 & 2 & 3 & 4 & 5 & 6 & 7 & 8 & 10 & 12 & 14 \\
\hline 0 & .5 & .5 & .5 & .5 & .5 & .5 & .34722 & .22222 & .12500 & .05556 & .03125 & .02000 & .01389 & .01020 & .0078I & .00500 & .00347 & .00255 \\
\hline 0.1 & .45025 & .449494 & .44698 & .44173 & .43008 & .39198 & .30445 & .20399 & .11806 & .05362 & .03045 & .01959 & & & & & & \\
\hline 0.2 & .40194 & .400434 & |39591. & .38660 & .36798 & .32802 & .26598 & .18633 & .11121 & .05170 & .02965 & 01919. & .01342 & |00991. & .00762 & & & \\
\hline 0.3 & .35633 & .35428 & .33809 & .33674 & .31578 & .28003 & .23311 & .16967 & .10450 & .04979 & .02886 & & & & & & & \\
\hline 0.4 & .31431 & .31214 & .30541 & .29298 & .27243 & .24200 & .20526 & .15428 & .09801 & & & & & & & & & \\
\hline 0.5 & .27639 & .27407 & .26732 & .25511 & .23639 & .21119 & .18168 & .14028 & .09180 & .04608 & .02727 & .01800 & .01272 & .00946 & .00734 & .00475 & .00332 & .00246 \\
\hline 0.6 & .24275 & .24247 & .2341I & .22289 & .20634 & .18520 & .16155 & .12759 & & & & & & & & & & \\
\hline 0.7 & .21327 & .21112 & .20535 & .19525 & 18093 & .16356 & | $|442|$ & .11620 & .08027 & & & & & & & & & \\
\hline 0.8 & .18765 & .18550 & .18049 & .17190 & .15977 & .14523 & .12928 & .10602 & & & & & & & & & & \\
\hline 0.9 & .16552 & .16337 & .15921 & .15179 & .14168 & .12954 & .11634 & .09686 & & & & & & & & & & \\
\hline 1 & .14645 & .14483 & .14610 & .13472 & .12618 & .11611 & .10510 & .08865 & .06552 & .03736 & .02352 & .01602 & .01157 & .00874 & .00683 & 3.00450 & .00318 & .00237 \\
\hline 1.2 & .11589 & .11435 & . 11201 & .10741 & .10140 & .09431 & .08657 & .07476 & .05728 & .03425 & .02208 & .01527 & .01113 & .00847 & .00664 & & & \\
\hline 1.5 & .08398 & .08356 & .08159 & .07885 & .07517 & .07088 & .06611 & .0587I & .04703 & .03003 & .02008 & .01419 & .01 & .00806 & .00636 & .00425 & .00304 & .00228 \\
\hline 2 & .05279 & .05105 & .05146 & .05034 & .04850 & .04675 & .04442 & .04078 & .03454 & .02410 & .01706 & .01248 & .00943 & .00738 & .00590 & . 00401 & .00290 & .00219 \\
\hline 2.5 & .03576 & .03426 & .03489 & .03435 & .03360 & .03211 & .03150 & .02953 & .02599 & .01945 & .01447 & .01096 & .00850 & .00674 & .00546 & .00378 & .00276 & .00210 \\
\hline 3 & .02566 & .02519 & .02470 & .0249I & .02444 & .02389 & .02330 & .02216 & .02007 & .01585 & .01230 & .00962 & .00763 & .00617 & .00505 & .00355 & .00263 & .00201 \\
\hline 4 & .01493 & .01452 & .01495 & .01526 & .014466 & .01418 & .01395 & .01356 & .01281 & .01084 & .00900 & .00742 & $.006 / 2$ & .00511 & .0043I & .00313 & .00237 & .00185 \\
\hline 5 & .00971 & .00927 & & & & .00929 & & & .00873 & .00774 & .00673 & .00579 & .00495 & .00425 & .00364 & +.00275 & .00213 & .00168 \\
\hline 6 & .00680 & & & & & .00632 & & & .00629 & .00574 & .00517 & .00457 & .00404 & .00354 & .00309 & 9.00241 & .00192 & .00154 \\
\hline 7 & .00503 & & & & & .00493 & & & .00466 & .00438 & .00404 & .00370 & .00330 & .00296 & .00264 & 4.00213 & .00172 & .00140 \\
\hline 8 & .00386 & & & & & .00377 & & & .00354 & .00344 & .00325 & .00297 & .00273 & .00250 & .00228 & 3.00185 & .00155 & .00127 \\
\hline 9 & .00306 & & & & & .00227 & & & .00275 & .00273 & .00264 & .00246 & .00229 & .00212 & .00194 & 4.00163 & .00139 & .00116 \\
\hline 10 & & & & & & & & .00210 & .00220 & .00225 & .00221 & .00203 & .00200 & .00181 & I.00171 & & & \\
\hline
\end{tabular}

\section{ANEXO 6: FUNÇÃO F}

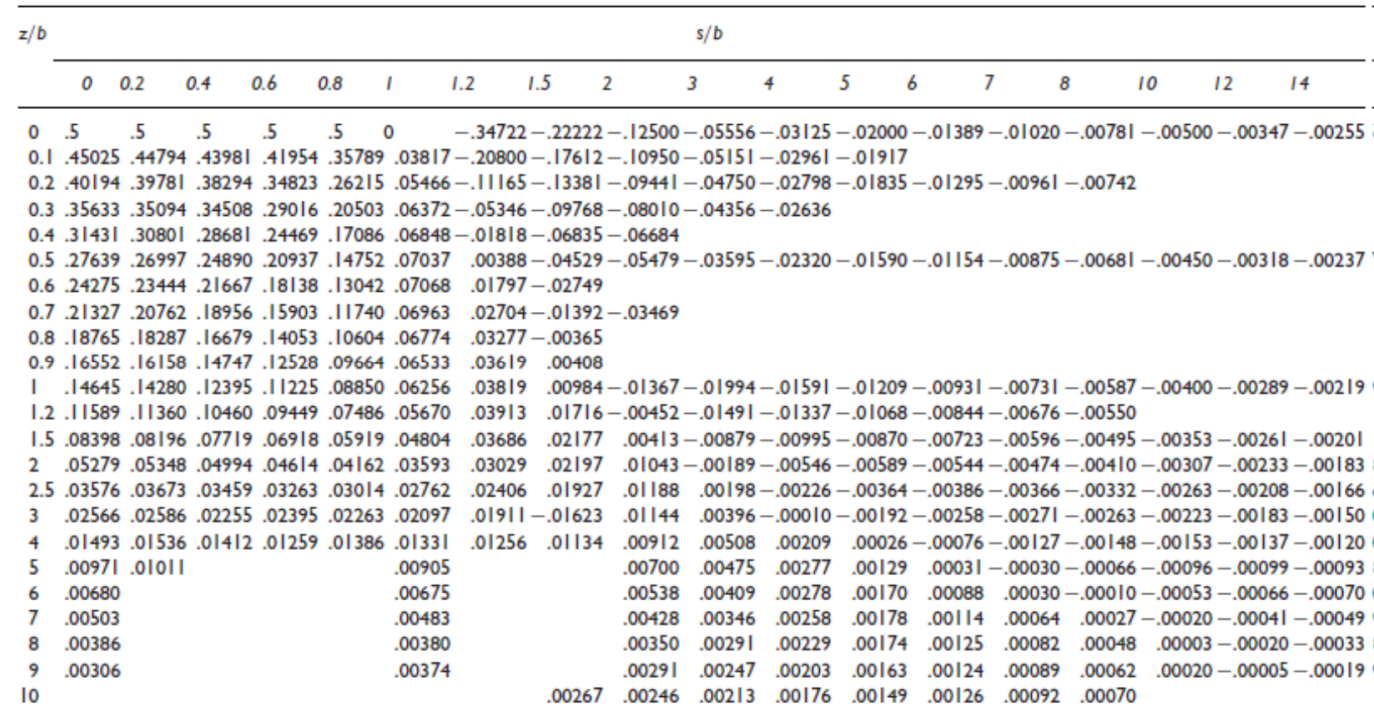




\section{ANEXO 7: FUNÇÃO G}

\begin{tabular}{|c|c|c|c|c|c|c|c|c|c|c|c|c|c|c|c|c|c|c|}
\hline \multirow[t]{2}{*}{$z / b$} & \multicolumn{18}{|c|}{$s / b$} \\
\hline & 00 & & 0.4 & 0.6 & 0.8 & 1 & 1.2 & 1.5 & 2 & 3 & 4 & 5 & 6 & 7 & 8 & 10 & 12 & 14 \\
\hline 0 & 00 & & 0 & 0 & 0 & .318310 & & 0 & 0 & 0 & 0 & 0 & 0 & 0 & 0 & 0 & 0 & 0 \\
\hline 0.1 & & .00315 & .00802 & .01951 & .06682 & .31405 & .05555 & .00865 & .00159 & .00023 & .00007 & .00003 & & & & & & \\
\hline 0.2 & & .01163 & .02877 & $.0644 \mid$ & .16214 & .30474 & .13592 & .03060 & .00614 & .00091 & .00026 & , .00010 & .00005 & .00003 & 3.00002 & & & \\
\hline 0.3 & & .02301 & .05475 & . 11072 & .21465 & .29228 & .18216 & .05747 & .01302 & .00201 & .00059 & & & & & & & \\
\hline 0.4 & & .03460 & .07883 & 14477. & 7.23442 & .27779 & .20195 & .08233 & .02138 & & & & & & & & & \\
\hline 0.5 & & .04429 & .09618 & 3. & .23652 & .26216 & .20731 & .10185 & .03033 & .00528 & .00158 & 3.00063 & .00030 & .00016 & 00009. & .00004 & .00002 & 2.00001 \\
\hline 0.6 & & .04966 & 10729. & . 17192 & .22949 & .24574 & .20496 & .11541 & & & & & & & & & & \\
\hline 0.7 & & .05484 & +.11256 & 6. & '. & .22924 & 19840 & .12373 & .04718 & & & & & & & & & \\
\hline 0.8 & & .05590 & .11225 & .16534 & |. & .21295 & .18953 & .12855 & & & & & & & & & & \\
\hline 0.9 & & .05496 & .10856 & .15628 & 3. 18904 & .19712 & 17945 & $.2888 \mathrm{I}$ & & & & & & & & & & \\
\hline I & & .05266 & 6. 10274 & 14566 & . .17419 & .18198 & .16884 & .12745 & .06434 & .01646 & .00555 & .00233 & .00113 & .00062 & .00036 & .00015 & .00007 & .00004 \\
\hline 1.2 & & .04585 & (08831 & .12323 & .14615 & .15408 & .14755 & .12038 & .06967 & .02077 & .00743 & .00320 & .00159 & .00087 & I.0005I & & & \\
\hline 1.5 & & .03483 & .06688 & .09293 & | & .11904 & .11830 & 10477 & .07075 & .02599 & .01021 & .00460 & .00233 & .00130 & .00078 & .00033 & .00016 & .00009 \\
\hline 2 & 0 & .02102 & 2.04069 & I.0572I & . .06948 & .07738 & .08067 & .07804 & .06275 & .03062 & .01409 & .00692 & .00369 & .00212 & 2.00129 & .00055 & .00027 & 7.00015 \\
\hline 2.5 & & .01293 & 3.02534 & .03611 & . .04484 & .05119 & .05509 & .05668 & .05117 & .03099 & .01650 & .00886 & .00499 & .00296 & 50185. & .00082 & 2.00041 & .00023 \\
\hline 3 & 0 & .00840 & .01638 & .02376 & .02994 & .03485 & .03843 & .04124 & .04039 & .02886 & .01745 & . .01022 & .00610 & .00376 & |.0024. & .00110 & .00057 & .00032 \\
\hline 4 & 0 & .00382 & .00772 & .01149 & .01480 & .01764 & .02004 & .02271 & .02475 & .02215 & . .01639 & . 01118 & .00745 & .00499 & .00340 & .00167 & .00090 & .00052 \\
\hline 5 & 0 & .00214 & & & & .00992 & & .01343 & .01551 & .01601 & .01364 & 4.01105 & .00782 & .00560 & .00404 & .00216 & . .00122 & 2.00073 \\
\hline 6 & 0 & & & & & .00602 & & .00845 & .01014 & .01148 & .01082 & 2.00917 & .00733 & .00567 & .00432 & .00243 & .00150 & . 00092 \\
\hline 7 & 0 & & & & & .00396 & & & .00687 & .00830 & .00842 & .00770 & .00656 & .00539 & .00432 & .00272 & 2.00171 & .00110 \\
\hline 8 & 0 & & & & & .00270 & & & .00481 & .00612 & .00656 & | & .00568 & .00492 & .00413 & .00278 & 3.00185 & 5.00124 \\
\hline 9 & 0 & & & & & .00177 & & & .00347 & .00459 & .00513 & 3.00515 & .00485 & .00438 & .0038I & .00274 & +.00192 & 2.00133 \\
\hline 10 & 0 & & & & & & & .00199 & .00258 & .00351 & .00407 & .00420 & I.004II & .00382 & 00346 & & & \\
\hline
\end{tabular}

